\title{
Impregnação do Bambu Dendrocalamus Giganteus Utilizando Nitrato de Cobre
}

\begin{abstract}
Monografia
Trabalho apresentado com requisito parcial à conclusão do Curso de Engenharia de Materiais e Nanotecnologia na Pontifícia Universidade Católica do Rio de Janeiro, Brasil.
\end{abstract}

Orientadora: Prof ${ }^{a}$. Sonia Letichevsky

Rio de Janeiro

Dezembro de 2016 


\section{Impregnação do Bambu Dendrocalamus Giganteus Utilizando Nitrato de Cobre}

Monografia apresentada com requisito parcial à conclusão do Curso de Engenharia de Materiais e Nanotecnologia na Pontifícia Universidade Católica do Rio de Janeiro, Brasil.

Profa $^{\text {a }}$ Sonia Letichevsky

Orientadora

Departamento de Engenharia de Materiais e Nanotecnologia - PUC - Rio

Prof. Roberto Ribeiro de Avillez

Coorientador - Coordenador da Engenharia de Materiais e Nanotecnologia

Departamento de Engenharia de Materiais e Nanotecnologia - PUC - Rio

Rio de Janeiro, 22 de Dezembro de 2016. 
Todos os direitos reservados. É proibida a reprodução total ou parcial do trabalho sem autorização da universidade, do autor e do orientador.

\section{Richard Bryan Magalhães Santos}

\section{Agradecimentos}

Eu, Richard Bryan, agradeço primeiramente a Deus por todas as coisas boas e más que me aconteceram. Cada uma delas, ao seu modo, me fez chegar aonde cheguei, e me fizeram ser quem eu sou.

A palavra que expressa admiração, respeito e carinho por meus professores é "agradecimento". Agradecer pela paciência, pela partilha de conhecimento, pelos ensinamentos para a vida. 


\section{Resumo}

Devido a uma maior preocupação com o meio-ambiente e materiais renováveis, e também a algumas de suas propriedades naturais; o bambu tem chamado atenção de engenheiros e cientistas dos ramos da civil e de materiais. Dentre essas propriedades podemos destacar: sua alta resistência à tração - comparável àquela do aço -, uma estrutura tubular reforçada por segmentos, que resulta em menor peso e providencia uma resistência a fraturas e flambagem, é um isolante térmico natural, o que auxilia na manutenção da temperatura no interior da construção. Ademais, ele é fácil de ser produzido, gera uma grande quantidade de $\mathrm{O}_{2}$ e ajuda a fixar $\mathrm{CO}_{2}$, sendo dessa maneira não apenas um bom material, mas também um material sustentável.

Um dos contrapontos, todavia, é o fato de que, como todo material biológico, ele está sujeito à degradação de agentes bacterianos e fúngicos. O presente trabalho visa à síntese e impregnação subsequente de nanopartículas de cobre no bambu de modo a aumentar sua resistência a agentes biológicos. Um trabalho anterior do grupo indica que isso pode ser alcançado com o uso de nanopartículas de prata. O método a ser descrito propõe uma variação do método anterior, visto que o cobre, assim como seu óxido, também é conhecido pelos seus efeitos antimicrobicida e antifungicida e são mais baratos.

Os materiais preparados foram caracterizados através de difração de raios-X e microtomografia de raios-X. Através de difração de raios-X observou-se que embora o cobre metálico não tenha sido obtido, foi possível, a partir do nitrato de cobre, produzir óxido de cobre I, bem como as fase triidroxi nitrato de cobre II e $\mathrm{Cu}_{4} \mathrm{O}_{3}$. Também foi feita uma avaliação da estrutura dos bambus pós-impregnação por microtomografia de raios-X, sendo possível observar uma penetração preferencial pelos canais xilema e floema do bambu. Foi possível obter nanopartículas de óxido de cobre $\mathrm{I}\left(\mathrm{Cu}_{2} \mathrm{O}\right)$ de diâmetro na faixa de $25 \mathrm{~nm}-41 \mathrm{~nm}$ e nanopartículas de paramelaconita $\left(\mathrm{Cu}_{4} \mathrm{O}_{3}\right)$ de diâmetro $9 \mathrm{~nm}-12 \mathrm{~nm}$, conforme observado pelos resultados obtidos por difração de raios-X

Palavras-chave: Bambu, nanopartículas, triidroxinitrato de cobre II, óxido de cobre I, paramelaconita e redução. 


\section{Sumário}

1. Introdução 06

2. Metodologia Experimental 09

$\begin{array}{ll}2.1 \text { Corte do bambu } & 09\end{array}$

2.2 Obtenção das amostras de bambu para impregnação com cobre $\quad 11$

2.3 Impregnação com o rotaevaporador $\quad 11$

2.4 Impregnação e redução simultânea com boroidreto de sódio 12

2.5 Redução da amostra 4

3. Caracterização dos compósitos obtidos 14

3.1 Difração de Raios-X 14

3.2 Microtomografia de Raios-X 14

4. Resultados e Discussão 15

4.1 Difração de Raios-X 15

$\begin{array}{ll}\text { 4.2 Microtomografia de Raios-X } & 27\end{array}$

5. Conclusão 33

6. Referências 33 


\section{Introdução}

O bambu é uma planta da família das gramíneas, como o arroz e o milho; possui diversos gêneros ao redor do mundo, como por exemplo: bambusa, fargesia e dendrocalamus. Os bambus são plantas angiospermas- são vascularizados, possuem flores, frutos e sementes - do tipo monocotiledôneas - possuem apenas um cotilédone, assim como o milho e o trigo - e pertencem à família das Poaceae (mesma das gramíneas), subfamília Bambusoideae. Devido a uma maior preocupação com o meioambiente e materiais renováveis, e também a algumas de suas propriedades naturais; o bambu tem chamado atenção de engenheiros e cientistas dos ramos da civil e de materiais. ${ }^{[1,2,]}$

Existem, aproximadamente, 75 gêneros de bambu e mais de 12.500 espécies do mesmo. Em geral, eles são ótimos substitutos para madeira, e caracterizam-se por serem de rápido crescimento, renováveis e capazes de produzir novos brotos sem a necessidade do replantio, tendo um rápido crescimento. Além disso, atualmente, os bambus têm um forte poder econômico, por conta de suas utilizações. Eles também têm uma importância ecológica, porque servem de comida a animais (como ursos panda), recuperam áreas degradadas e também atuam como bioindicadores da erosão do solo. Assim, o bambu é um importante regenerador ambiental, devido a seu sistema radicular, podendo ser utilizado em reflorestamentos. ${ }^{[1,2,3]}$

No presente trabalho, foi utilizado o bambu da espécie Dendrocalamus giganteus, que é encontrada em ambientes de clima tropical e subtropical, e cresce em solos argilosos. É a espécie de bambu conhecida por ser a mais alta de todas- além de ter um dos maiores colmos- e, portanto, é classificada como um bambu de porte alto. Ela é nativa do continente asiático, mais especificamente da Malásia, de Mianmar, do Sul da China e Noroeste da Tailândia e também é cultivada em diversos locais, como na Índia e no Brasil. Seu ciclo de floração é de 30 a 40 anos: quando ele ocorre, há a propagação das sementes, mas, ao mesmo tempo, a planta morre. Além disso, em um mesmo indivíduo desta espécie é possível observar colmos de diferentes idades. A figura 1 representa um espécime de Dendrocalamus Giganteus. ${ }^{[2,3,4,5,6]}$ 


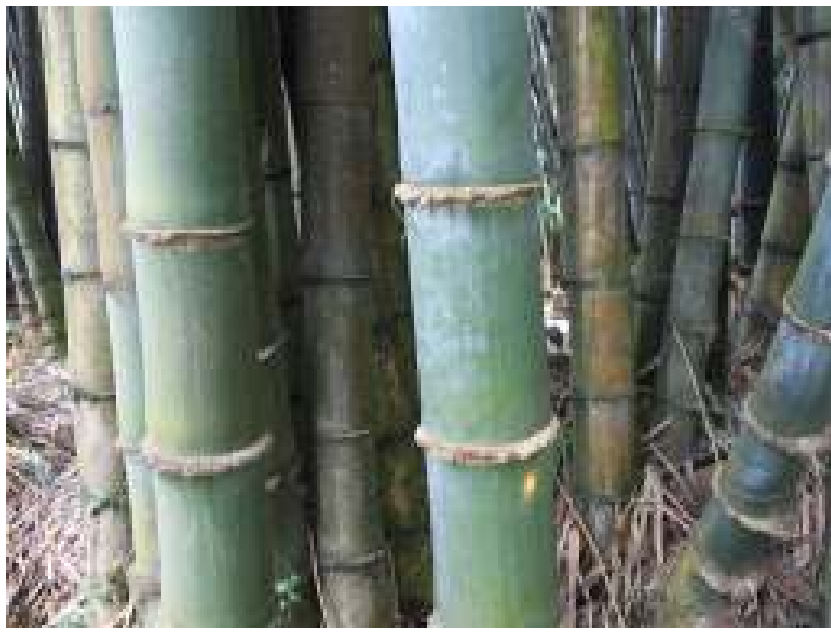

Figura 1. Representação do bambu Dendrocalamus Giganteus. ${ }^{[7]}$

O colmo é um tipo de caule caracterizado pela fácil visibilidade dos nós e entrenós, que é oco nas espécies de bambu. No caso do D. giganteus, os colmos têm, em geral, altura entre 25 e 40 metros (podendo crescer, em um só dia, mais de 1 metro), 15 a 25 centímetros de diâmetro, 2 a 2,5 $\mathrm{cm}$ de espessura de parede, cor verde, ramificado na parte superior, possui nós e entrenós de 37 a 40 centímetros de comprimento, cobertos com descamação branca e mole quando jovens. As bainhas medem de 30 a 50 $\mathrm{cm}$ de comprimento e são amplas e lisas. ${ }^{[2,3,8]}$

Nos bambus, os entrenós e nós (figura 2) fazem parte do colmo. As células são orientadas axialmente pelos entrenós e fazem interconexões transversais em nós. Há uma ramificação de vasos intensiva dentro dos nós. São duas as camadas que revestem o colmo (camadas epidérmicas), sendo a interna mais espessa e lignificada (a lignina é um polímero cuja função estrutural proporciona à planta propriedades de elasticidade e resistência). Em geral, 50\% do colmo é parênquima, 40\% fibra (celulose, hemicelulose e lignina) e $10 \%$ tecido condutor, variando de espécie a espécie. ${ }^{[2,5]}$

As folhas do D. giganteus variam em tamanho, mas em geral são grandes, arredondadas na base, possuem de 30 a 50 centímetros por 1 centímetro de espessura, e são, em um primeiro momento, cabeludas. São agudas e verdes de início. Depois, tornam-se amareladas e pardo-claras. ${ }^{[2,3,8]}$ 


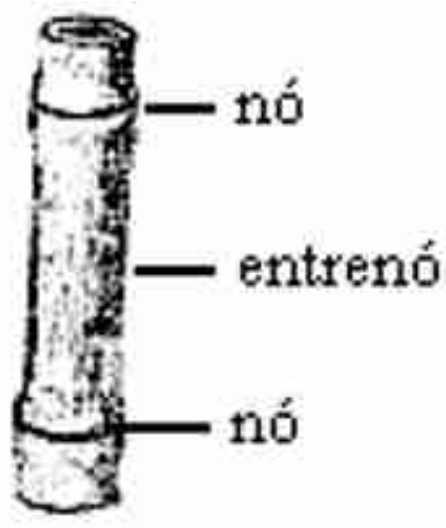

Figura 2. Representação dos nós e entrenós. [9]

Os estômatos, estrutura responsável pela transpiração e fotossíntese das plantas, do Dendrocalamus giganteus são grandes e distintos, e estão distribuídos pela superfície dos colmos. Há células da epiderme grandes e pequenas nessa espécie. Apesar dos espinhos não serem comuns em bambus, a espécie $D$. giganteus os possui, esquema que pode ser visualizado na figura 3 . $^{[1,5]}$

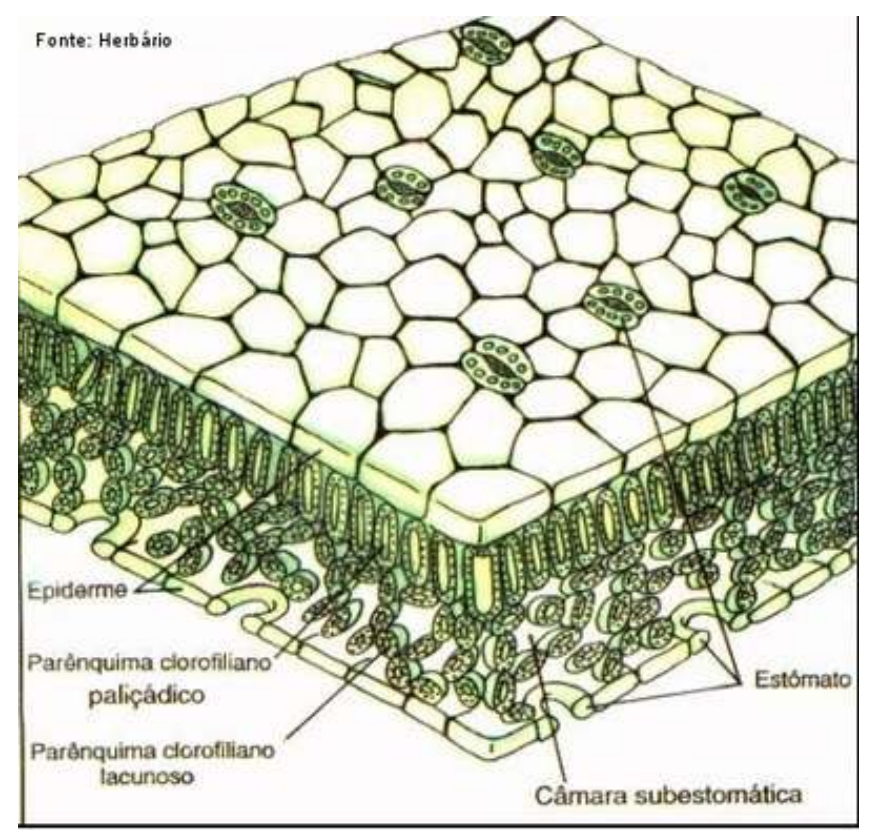

Figura 3. Esquema representativo dos estômatos. ${ }^{[10]}$

O metaxilema e o floema (figura 3) estão rodeados por bainhas de esclerênquima no colmo do bambu. Eles diferem consideravelmente em tamanho, forma e localização de acordo com a posição no colmo e com a espécie de bambu. O floema é o tecido condutor responsável pelo transporte da seiva elaborada (composta principalmente por açúcares provenientes da fotossíntese e água) dos colmos (órgãos ricos em estômatos e, 
consequentemente, em cloroplastos e responsáveis pela fotossíntese e pela transpiração) para o resto da planta. ${ }^{[5]}$

Apesar do Dendrocalamus giganteus poder ser amplamente utilizado como material de construção, esta espécie de bambu também pode ser degradada devido a insetos e fungos. Os principais fungos que infectam esse bambu são: Arthrinium $s p$, Fusarium sp, Acremonium e Trichoderma sp, mas principalmente o primeiro, que vive no solo e facilmente infecta o $D$. giganteus. ${ }^{[11,12]}$

O presente trabalho visa à impregnação de nanopartículas de cobre no bambu de modo a aumentar sua resistência a agentes biológicos. Um trabalho anterior realizado no Departamento de Química da PUC-Rio ${ }^{[13]}$ apresenta a impregnação de bambu com nanopartículas de prata com o mesmo objetivo deste trabalho.

O método a ser descrito propõe um desenvolvimento alternativo do método anterior, visto que o cobre/óxido de cobre também é conhecido pelo seu efeito antimicrobiano e antifúngico e é uma alternativa mais atrativa financeiramente.

\section{Metodologia Experimental}

\section{1 - Corte do Bambu}

A retirada da amostra foi feita no campus da PUC no dia 29.07.2016. O bambu foi marcado no dia anterior. A figura 4 apresenta a foto do bambu retirado, e na figura 5, uma foto do bambuzal da espécie DG plantado no campus da PUC-Rio.

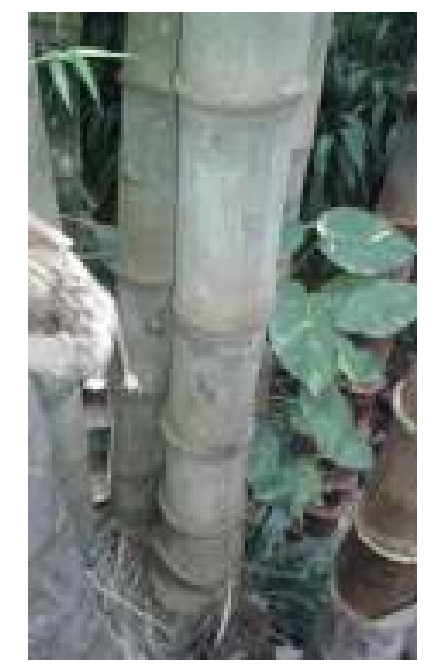

Figura 4. Bambu Dendrocalamus Giganteus escolhido. 


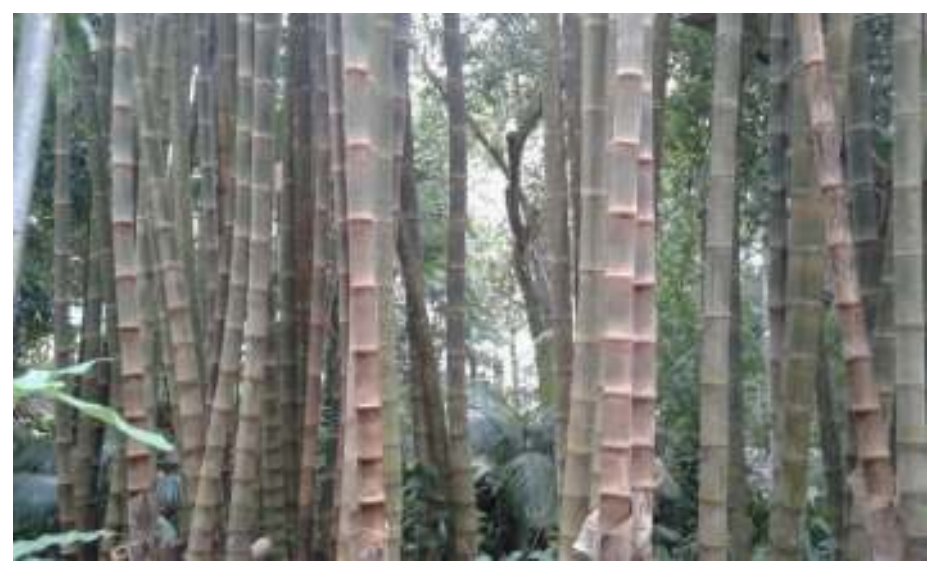

Figura 5. Bambuzal da espécie Dendrocalamus Giganteus.

Os colmos escolhidos foram retirados da base, do meio e do topo da planta. A figura 6 ilustra a localização dos entrenós na planta.

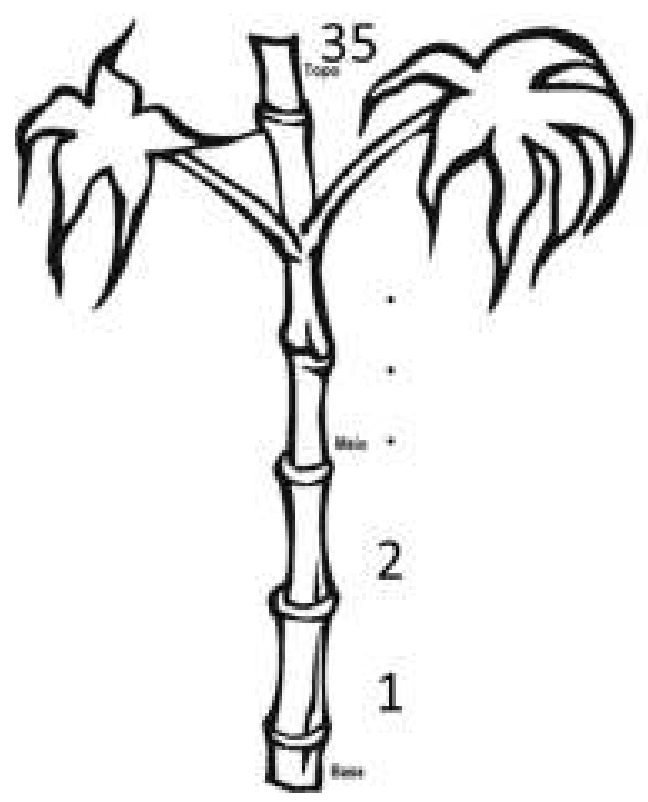

Figura 6. Representação das localidades da planta donde a amostra de bambu foi extraída (colmo 35). ${ }^{[14]}$

Os colmos escolhidos para representar essas partes foram o número 4- 5 (90 cm do solo), os números 21 (8,45 m) e 34-35 (15,34m) do topo. Sendo somente esta última parte utilizada neste presente trabalho. As amostras, por estarem muito úmidas, foram deixadas no terraço do Departamento de Química de sexta-feira (29.07.2016) até sextafeira (12.08.2016) quando foram iniciados os cortes dos fragmentos em pedaços menores com uma motosserra para o corte mais refinado adiante. 


\section{2 - Obtenção das amostras de bambu para impregnação com cobre}

Com uma máquina de corte de precisão micrométrica foram obtidas as amostras utilizadas durante o trabalho. Elas possuem dimensões 1,8 x 1,2 x 0,5 cm (comprimento $\mathrm{x}$ espessura $\mathrm{x}$ largura), com a espessura tendo uma variação um pouco maior em torno do valor mencionado. A figura 7 representa um colmo do bambu e uma amostra do mesmo cortada segundo o padrão supracitado. Os colmos escolhidos para os experimentos foram os 34 e 35 .

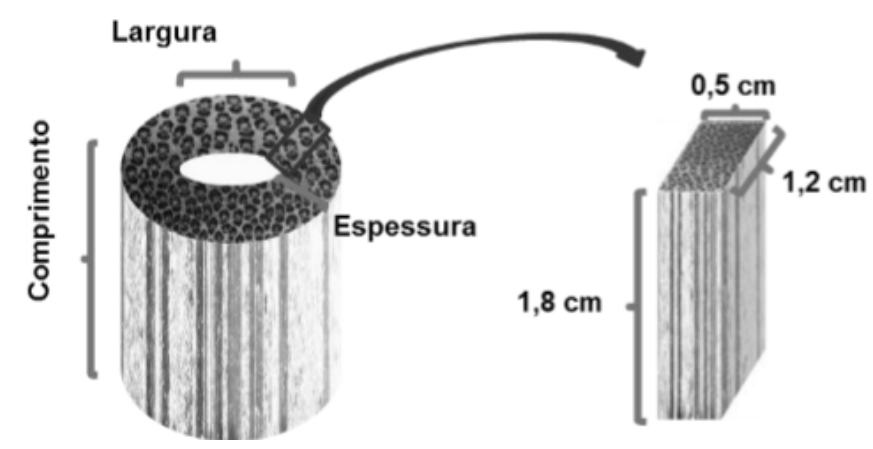

Figura 7. Esquema de corte do bambu. ${ }^{[13]}$

\section{3 - Impregnação com o rotaevaporador}

O método escolhido para inserir o cobre no bambu consiste numa impregnação úmida de nitrato de cobre $\left(\mathrm{Cu}\left(\mathrm{NO}_{3}\right)_{2} \cdot 3 \mathrm{H}_{2} \mathrm{O}\right)$, da Vetec com o auxílio do rotaevaporador. Como se trata de um sal muito higroscópico, o mesmo foi seco em dessecador com sílica gel e com auxílio de uma bomba de vácuo por um período mínimo de $24 \mathrm{~h}$.

Foi preparada uma solução $1 \mathrm{M}$ de $\mathrm{Cu}\left(\mathrm{NO}_{3}\right)_{2} \cdot 3 \mathrm{H}_{2} \mathrm{O}$ em $50 \mathrm{~mL}$ de água. Como o bambu flutua sobre a solução, uma pedra de granito foi enrolada em teflon e amarrada ao bambu com fio dental para que ele pudesse ficar imerso na solução. O bambu foi então colocado num balão de $125 \mathrm{~mL}$ junto a um adaptador, e o conjunto foi colocado no rotaevaporador.

Foram feitas algumas impregnações sem o auxílio da temperatura com a expectativa de que a mera penetração do líquido no material pudesse reduzi-lo e esse procedimento deu origem às amostras $\mathrm{A}, \mathrm{B}$ e $\mathrm{C}$. Também foram realizadas impregnações com o auxílio de aquecimento e com etanol como solvente e agente 
redutor do cobre, conforme descrito a seguir. A tabela 1 sumariza o procedimento adotado para cada amostra.

$\mathrm{O}$ rotaevaporador foi colocado a $50^{\circ} \mathrm{C}$ num primeiro momento. Ao passo que o etanol evaporado condensava-se no adaptador, a temperatura foi aumentada até $80^{\circ} \mathrm{C}$, a partir do qual o equilíbrio atingido com o etanol condensado impedia a evaporação. $\mathrm{O}$ adaptador foi retirado e o etanol removido, o sistema foi remontado e a evaporação foi, então, quase instantânea, deixando o pedaço de bambu envolto pelo sólido remanescente devido a uma alta concentração de nitrato de cobre utilizada.

Tabela 1. Condições de impregnação das amostras.

\begin{tabular}{|c|c|c|c|}
\hline $\begin{array}{c}\text { NOME DA } \\
\text { AMOSTRA }\end{array}$ & TEMPERATURA & SOLVENTE & $\begin{array}{c}\text { TEMPO } \\
\text { TOTAL } \\
\text { (h) }\end{array}$ \\
\hline A & Não & Água & 8 \\
\hline B & Não & Água & 12 \\
\hline C & Não & Água & 16 \\
\hline 1 & Sim & Etanol & 5 \\
\hline 2 & Sim & Etanol & 5 \\
\hline 3 & Sim & Etanol* & 5 \\
\hline 4 & Sim & Etanol & 5 \\
\hline
\end{tabular}

* com boroidreto de sódio e hidróxido de amônio adicionados.

O excesso de nitrato, sal que não penetrou nos canais do bambu, formou uma capa sobre a superfície do mesmo. Esta capa foi retirada com uma espátula, e o bambu foi lavado com etanol e posteriormente seco numa estufa a $60^{\circ} \mathrm{C}$ por uma hora. As amostras obtidas através desse procedimento foram identificadas como $1,2,3$ e 4 . O procedimento diferenciado da amostra 3 é explicado na seção 2.4.

\section{4 - Impregnação e redução simultânea com boroidreto de sódio}

A impregnação foi feita de modo similar àquela pelo rotaevaporador: foram usados $20 \mathrm{~mL}$ de etanol e $20 \mathrm{~mL}$ da solução de nitrato de cobre $1 \mathrm{M}$. O boroidreto foi usado com o objetivo de transformar o nitrato de cobre em óxido de cobre ou até mesmo em cobre metálico ainda em solução, porém como o boroidreto de sódio degrada a temperatura ambiente em meio levemente ácido, a solução foi alcalinizada com uma 
solução de $1 \mathrm{M}$ de hidróxido de amônio até atingir o pH 10. A essa solução foi adicionado $0,23 \mathrm{~g}$ do boroidreto de sódio e logo após uma nova amostra de bambu puro. A solução com o bambu foi então submetida ao mesmo procedimento de aquecimento e evaporação retratado na seção 2.3. Ao término da evaporação, o bambu apresentou cor negra e aparentemente uma casca. A amostra obtida através deste procedimento foi identificada como 3.

\section{5 - Redução da amostra 4}

A redução do $\mathrm{Cu}_{2}\left(\mathrm{NO}_{3}\right)(\mathrm{OH})_{3}$ (Triidroxi nitrato de cobre II) foi realizada através de uma reação com o boroidreto de sódio $\left(\mathrm{NaBH}_{4}\right)$, de acordo com o seguinte procedimento. Dissolveu-se 0,31g de boroidreto de sódio em $20 \mathrm{~mL}$ de água deionizada a $\mathrm{pH}=8$ (ajustada com $\mathrm{NH}_{4} \mathrm{OH}$ ). Aqueceu-se a $70^{\circ} \mathrm{C}$ na manta de aquecimento e o bambu foi colocado conforme a figura 8 (contato apenas com o vapor de $\mathrm{H}_{2}$ gerado pelo $\mathrm{NaBH}_{4}$ ). Esperou-se 30 min e retirou-se o bambu.

O bambu apresentou uma cor negra como pode ser visto na figura 9.

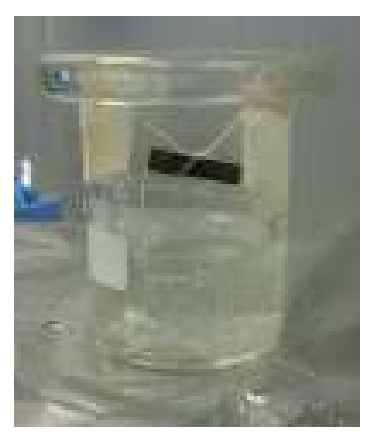

Figura 8. Esquema para a reação entre o triidroxi nitrato e o gás $\mathrm{H}_{2}$ liberado pelo boroidreto de sódio.

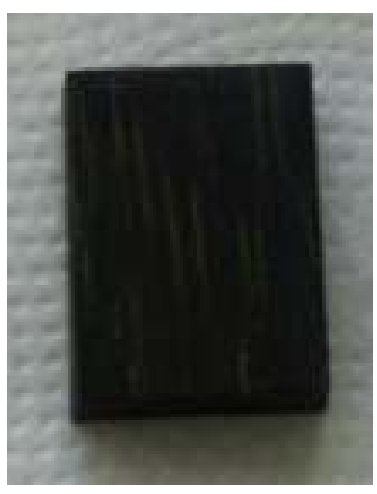

Figura 9. Amostra de bambu após a tentativa de redução. 
O pedaço foi então guardado por 48 horas, apresentando por fim novamente uma cor esverdeada. A amostra que passou por esse procedimento foi a amostra 4.

\section{Caracterização dos compósitos obtidos}

\section{1 - Difração de Raios-X}

A difração de raios-X foi a técnica utilizada inicialmente para identificar e caracterizar as amostras preparadas assim como o bambu in natura, pois é o principal método de determinação da estrutura cristalina de um material. $\mathrm{O}$ equipamento utilizado foi um difratômetro D8-Discover da Bruker nas seguintes condições: tubo de cobre com comprimento de onda de $1,54 \AA$, operando a $40 \mathrm{kV}$ e $40 \mathrm{~mA}$. Os difratogramas foram coletados na faixa de $2 \theta$ de 5 a $90^{\circ}$ com passo de $0,02^{\circ}$ e 25 s por passo.

A análise do difratograma foi realizada com auxílio de dois softwares da Bruker: DIFFRAC.EVA e DIFFRAC.TOPAS os quais foram utilizados para fazer uma identificação das fases que apareceram nas amostras impregnadas e para uma análise quantitativa das mesmas segundo o método de Rietveld ${ }^{[15]}$, respectivamente.

\section{2 - Microtomografia de Raios-X}

O microtomógrafo usado para a análise da amostra de bambu foi um ZEISS Xradia 510 Versa da empresa ZEISS, sediado no Laboratório de Processamento Digital de Imagens (LPDI) do Departamento de Engenharia Química e de Materiais (DEQM) da PUC-Rio. A análise foi feita utilizando uma voltagem de $50 \mathrm{kV}$, uma corrente de 0,80 mA; distância de $42 \mathrm{~mm}$ entre a fonte e a amostra, distância de $100 \mathrm{~mm}$ entre a amostra e o detector e tempo de exposição de 2,2 s. Foi utlizada a lente objetiva macro de $0,4 \mathrm{X}$, com resolução de $20 \mu \mathrm{m}$. As figuras 10 e 11 retratam o equipamento, bem como o posicionamento de uma amostra exemplo. 


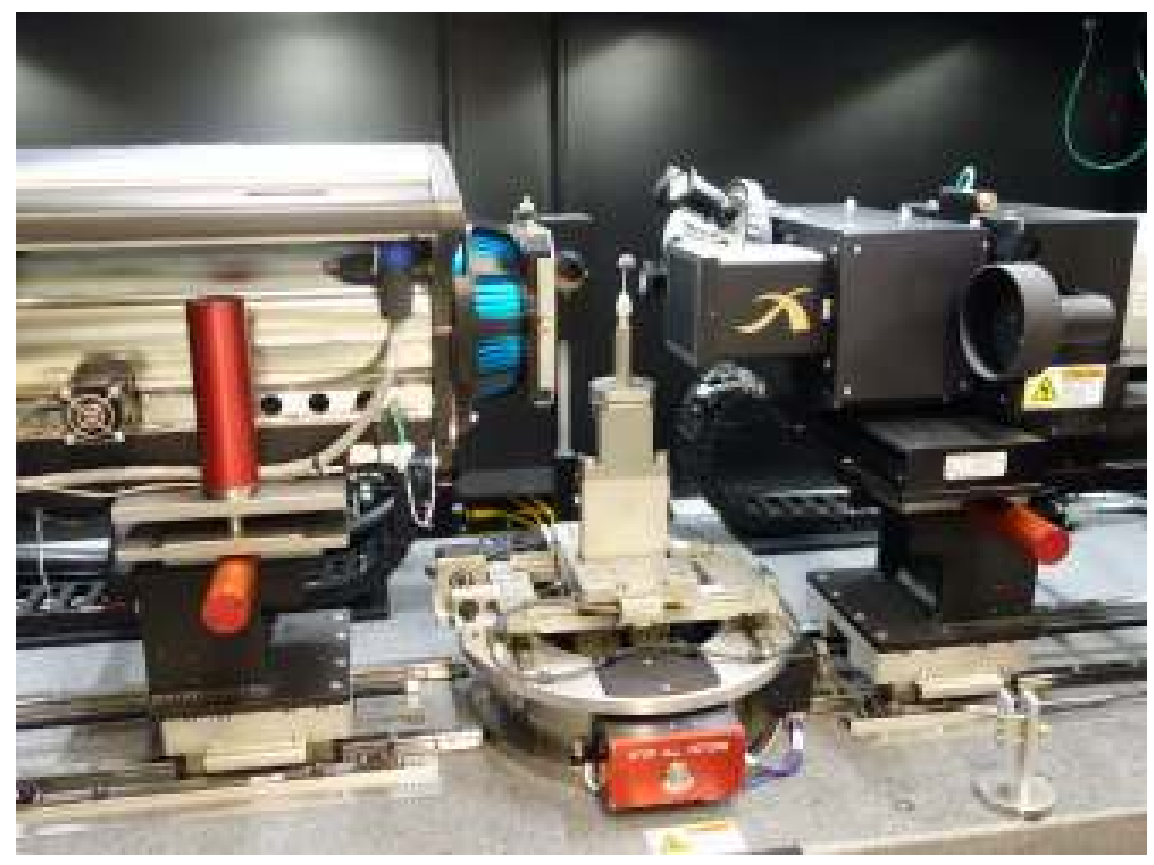

Figura 10. Microtomógrafo onde foram analisadas as amostras. ${ }^{[16]}$

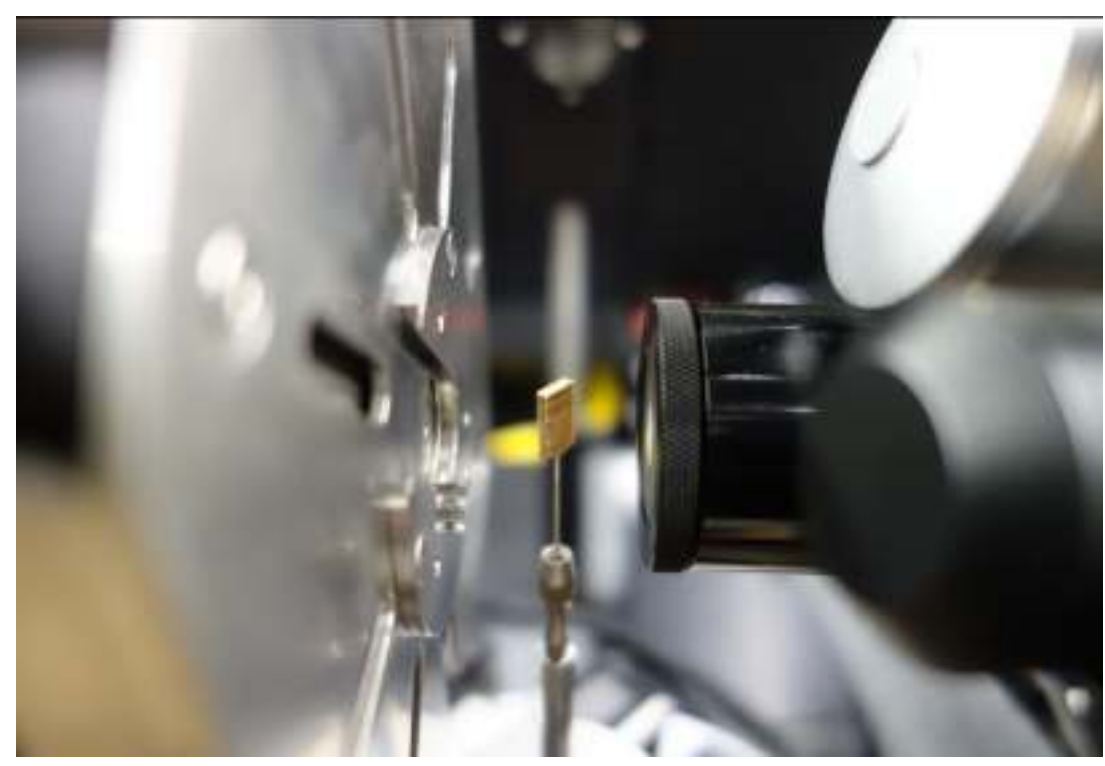

Figura 11. Esquema representando o posicionamento da amostra quanto à fonte e ao detector. ${ }^{[16]}$

\section{Resultados e Discussão}

\section{1 - Difração de Raios-X}

Acreditava-se que o amido presente no bambu fosse capaz de reduzir o $\mathrm{Cu}^{2+}$ a cobre metálico ${ }^{[17]}$, dessa forma foi utilizado como precursor uma solução de nitrato de cobre triidratado. Como o difratograma do bambu não se encontra na base de dados de cristalografia que utilizamos no programa EVA, fez-se necessária uma análise prévia do 
difratograma de um bambu puro. Assim seria possível identificar quais picos seriam oriundos da impregnação e quais seriam inerentes ao bambu.

A figura 12 retrata o difratograma de um bambu puro. Ela, assim como os outros difratogramas a seguir, foi retirada do TOPAS como um arquivo de texto e plotada no programa Origin8pro.

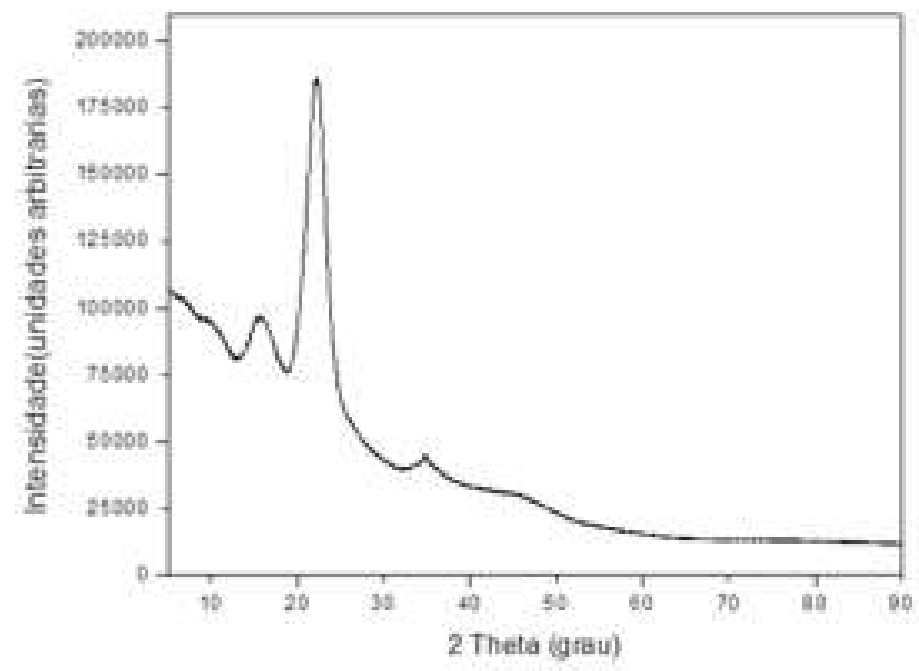

Figura 12. Difratograma do bambu puro.

Os resultados obtidos para as primeiras tentativas de impregnação - amostras A, B e C (Tabela 1) - geraram difratogramas que não apresentaram nenhum indício de impregnação. Todavia, isso não significa que a mesma não ocorreu. A impregnação pode ter ocorrido a níveis não detectáveis através de DRX (abaixo do limite de detecção da técnica). A figura 13 exibe esses resultados.

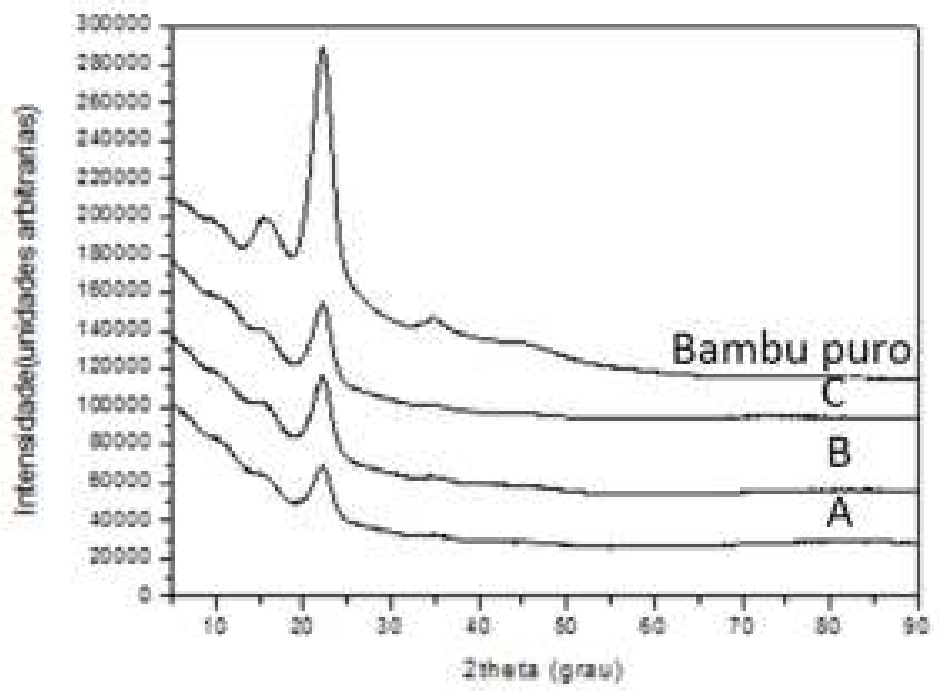


Figura 13. Difratograma do bambu puro, e das amostras A, B, e C.

Após estes resultados, fez-se necessária alteração do método de impregnação. Foi introduzido aquecimento e a água foi substituída por etanol em mesma quantidade, pois além de fornecer uma evaporação mais rápida devido ao menor ponto de ebulição, também é um agente redutor. A figura 14 ilustra a aparência dessas amostras pósimpregnação.

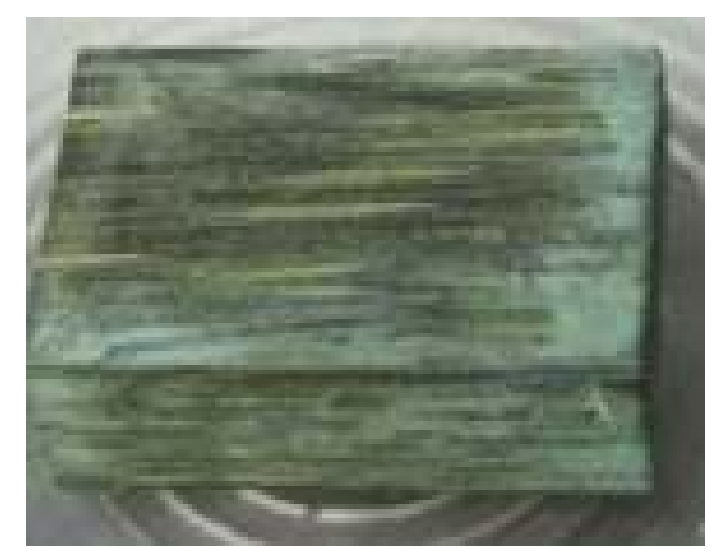

Figura 14. Amostra de bambu pós-impregnação.

O método de impregnação com etanol e aquecimento da solução produziu resultados interessantes, onde ficam perceptíveis as introduções de novos picos ao difratograma de referência do bambu puro. Isso pode ser observado na figura 15, a qual exibe o difratograma da amostra 1.

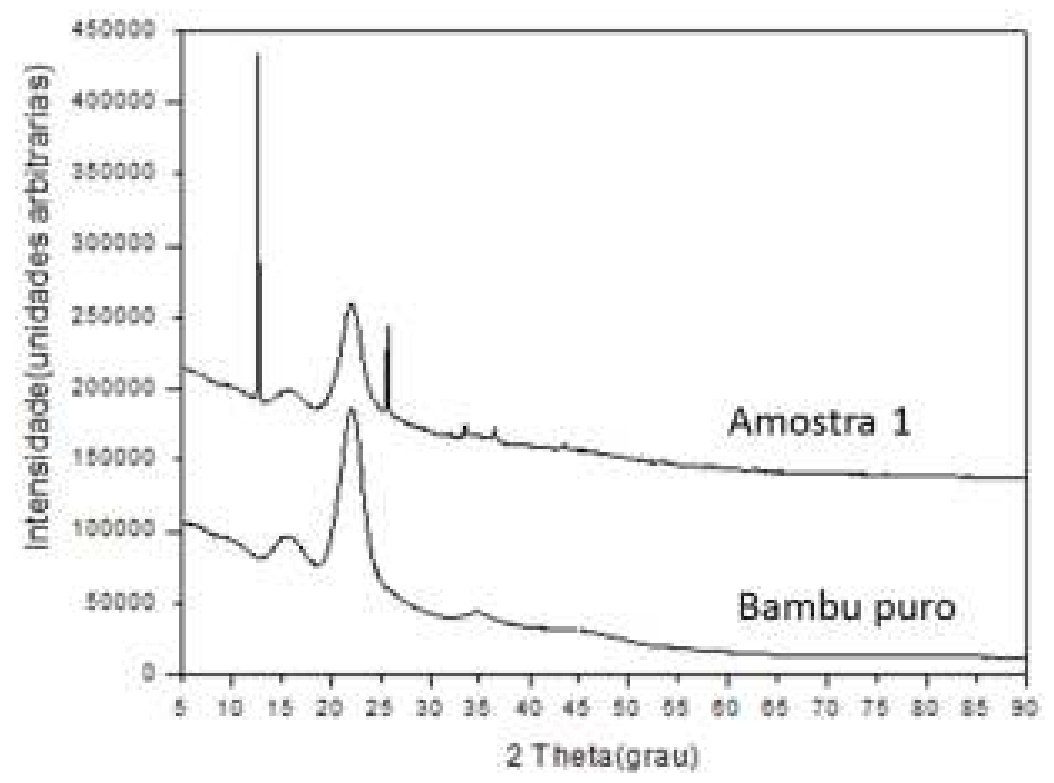

Figura 15. Difratograma do bambu puro e da amostra 1. 
Com o ajuste feito pelo método de Rietveld, foi possível confirmar a presença do Triidroxi nitrato de cobre II, mas também do óxido de cobre I, além da paramelaconita $\left(\mathrm{Cu}_{4} \mathrm{O}_{3}\right)$. As figuras 16, 17, 18 e 19 mostram os ajustes feitos com o programa TOPAS que salientam a correspondência dos picos com as suas fases. Ademais, o método permite quantificar a composição das fases impregnadas. Por ser uma amostra complexa, foram ajustados os diferentes padrões de difratogramas para as fases presentes, o que também pode ser visto nas figuras 16 a 19.

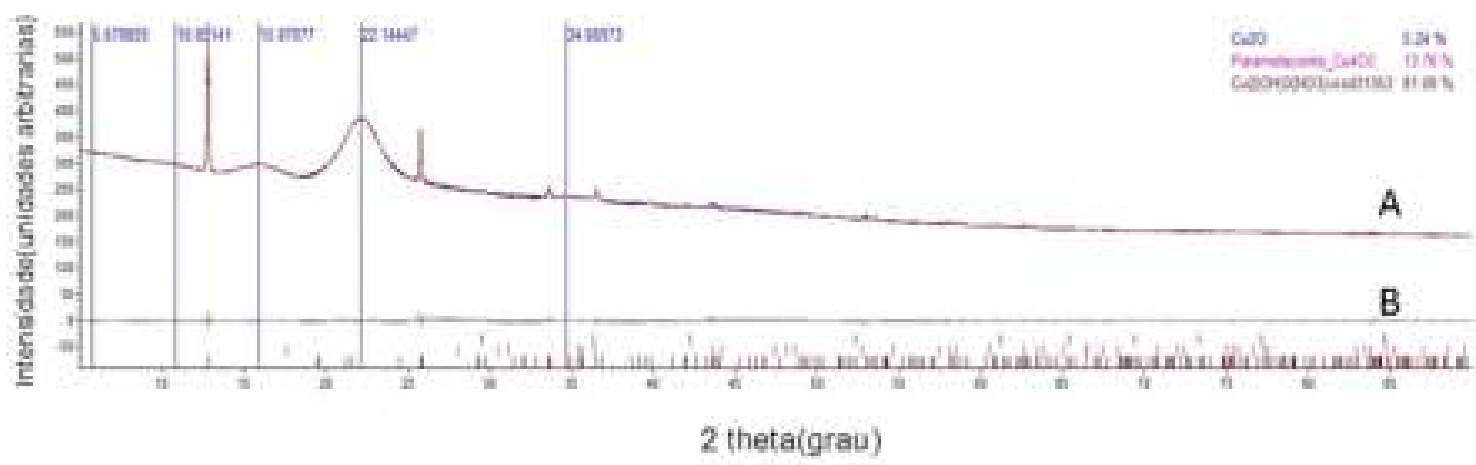

Figura 16. Difratograma da amostra 1 (A). A linha cinza (B) em zero refere-se à diferença entre o difratograma ajustado (linha vermelha) e o obtido experimentalmente.

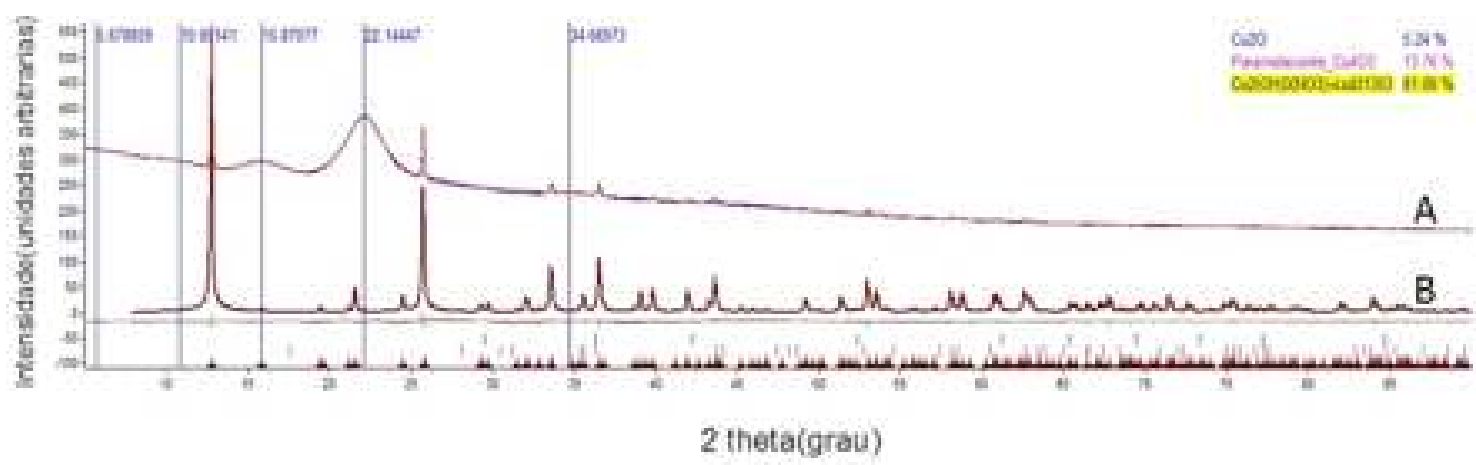

Figura 17. Difratograma da amostra 1 (A) e difratograma da fase triidroxi nitrato de cobre II (B).

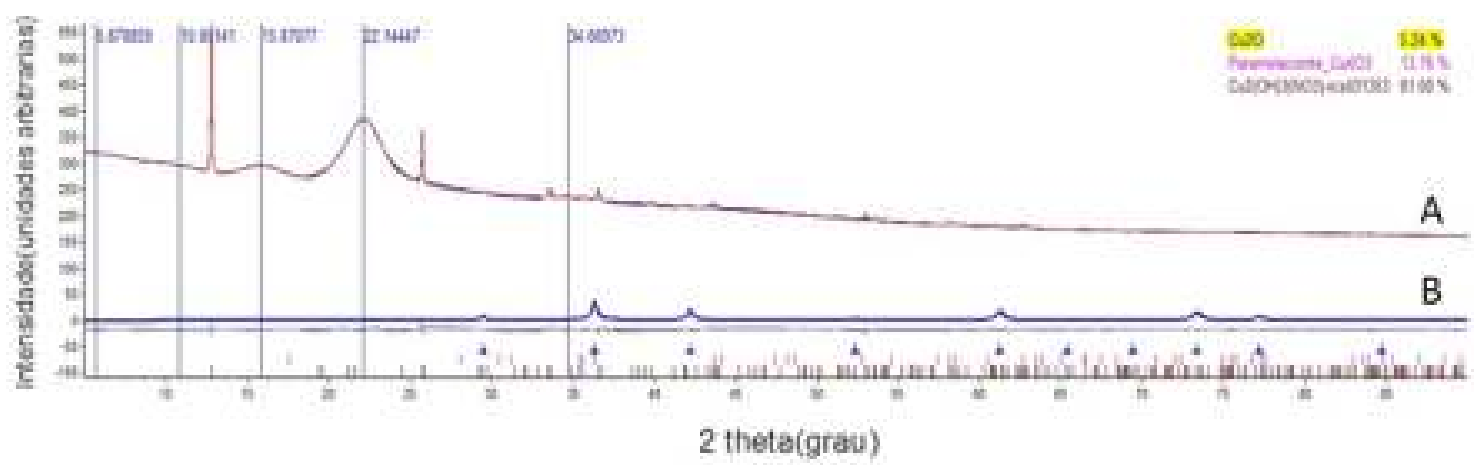


Figura 18. Difratograma da amostra 1 (A) e difratograma da fase $\mathrm{Cu}_{2} \mathrm{O}$ (B).

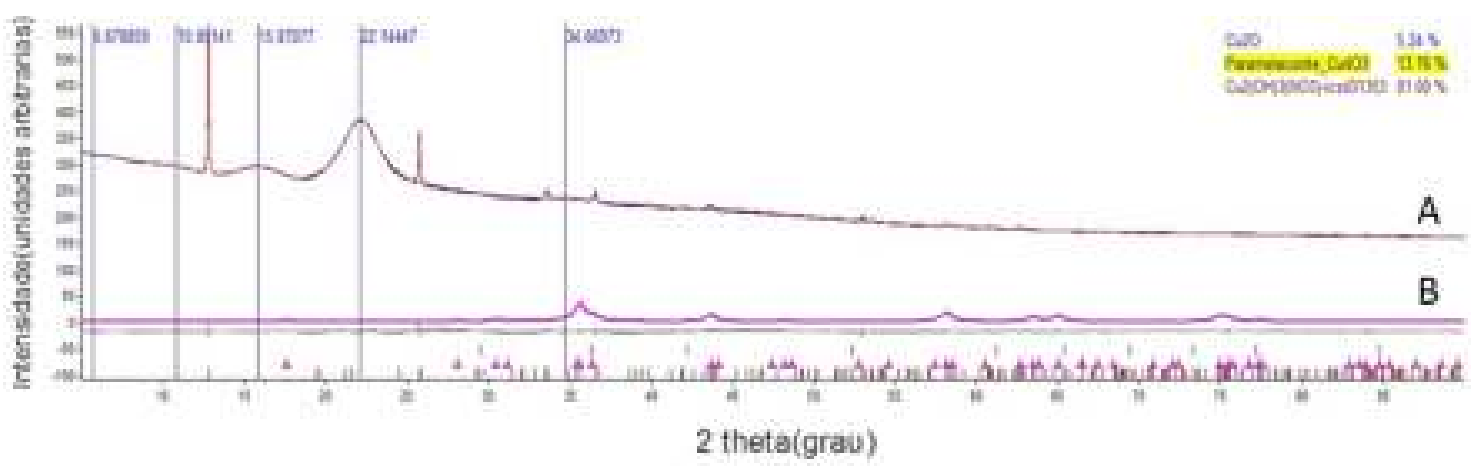

Figura 19. Difratograma da amostra 1 (A) e difratograma da fase paramelaconita (B).

Para que houvesse uma garantia da reprodutibilidade do método, o procedimento de síntese foi repetido mais duas vezes, gerando as amostras 2 e 4 . Os difratogramas relativos as mesmas podem ser vistos na figura 20. As figuras 21,22 e 23 demonstram o difratograma da amostra 2, assim como sua análise no TOPAS, que indicam que houve uma reprodutibilidade qualitativa dos resultados devido à semelhança com os resultados anteriores.

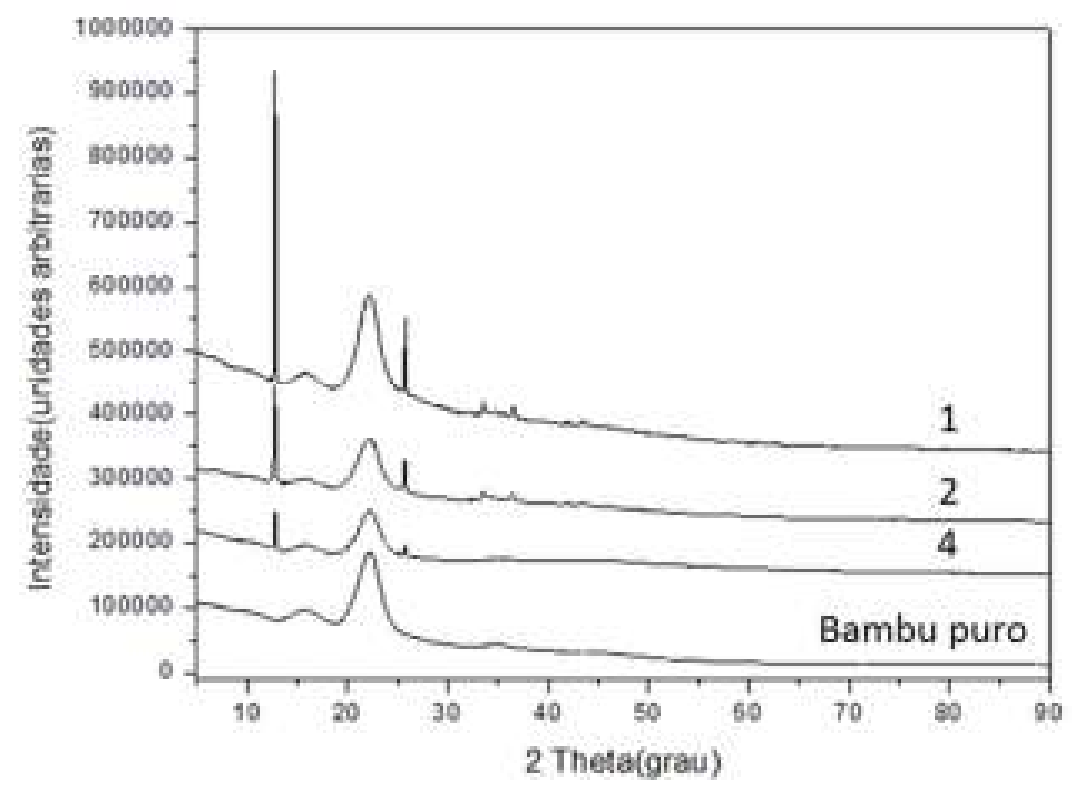

Figura 20. Difratograma do bambu puro e das amostras 1, 2 e 4. 


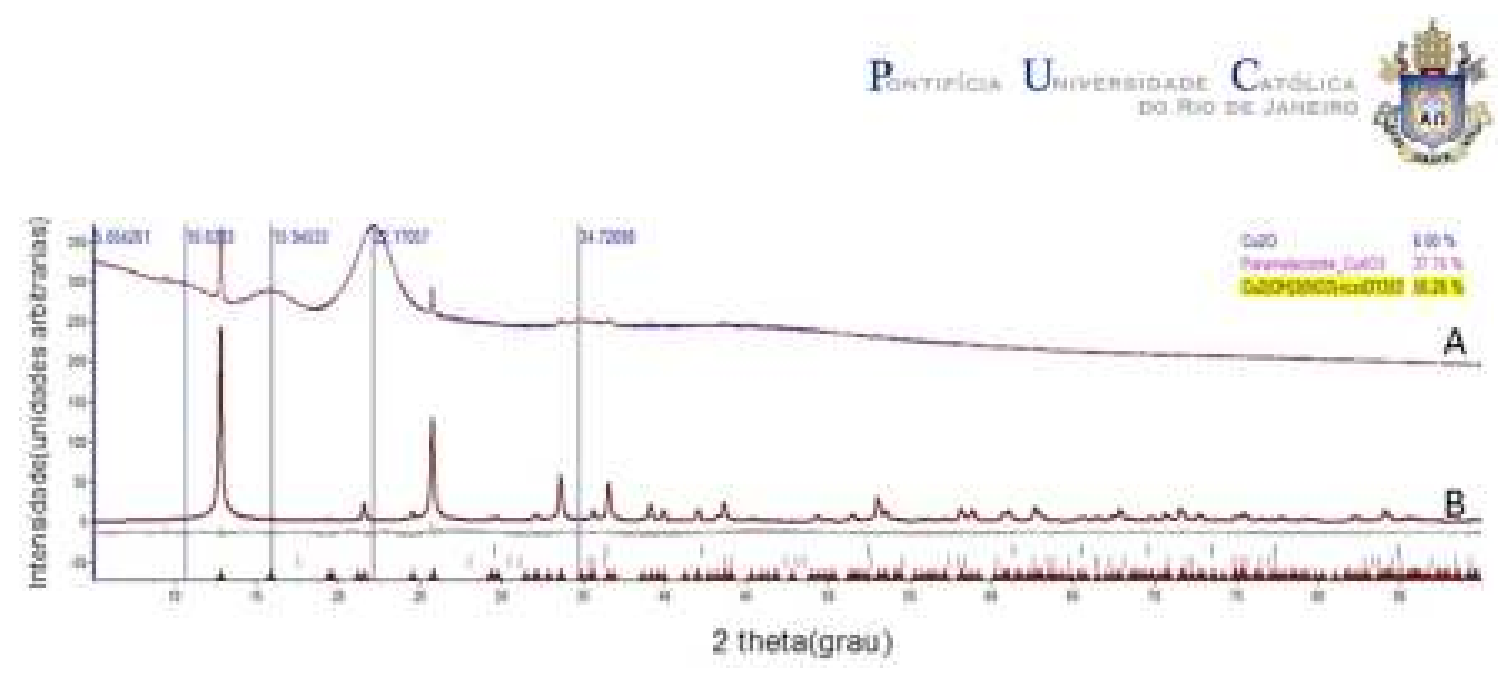

Figura 21. Difratograma da amostra 2 (A) e difratograma da fase triidroxi nitrato de cobre 2 (B).

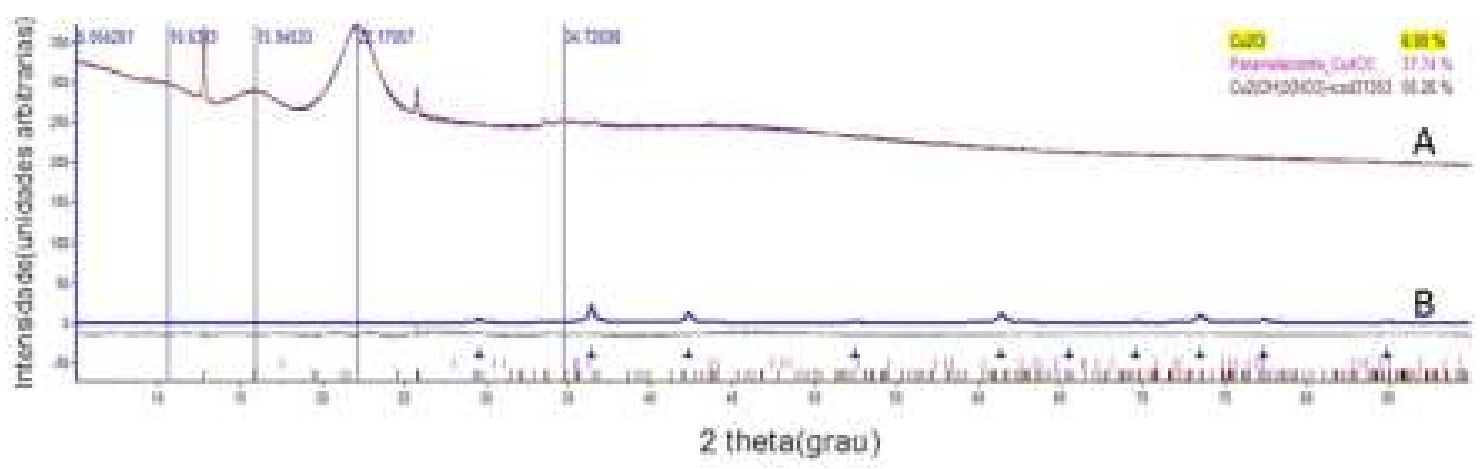

Figura 22. Difratograma da amostra 2 (A) e difratograma da fase paramelaconita (B).

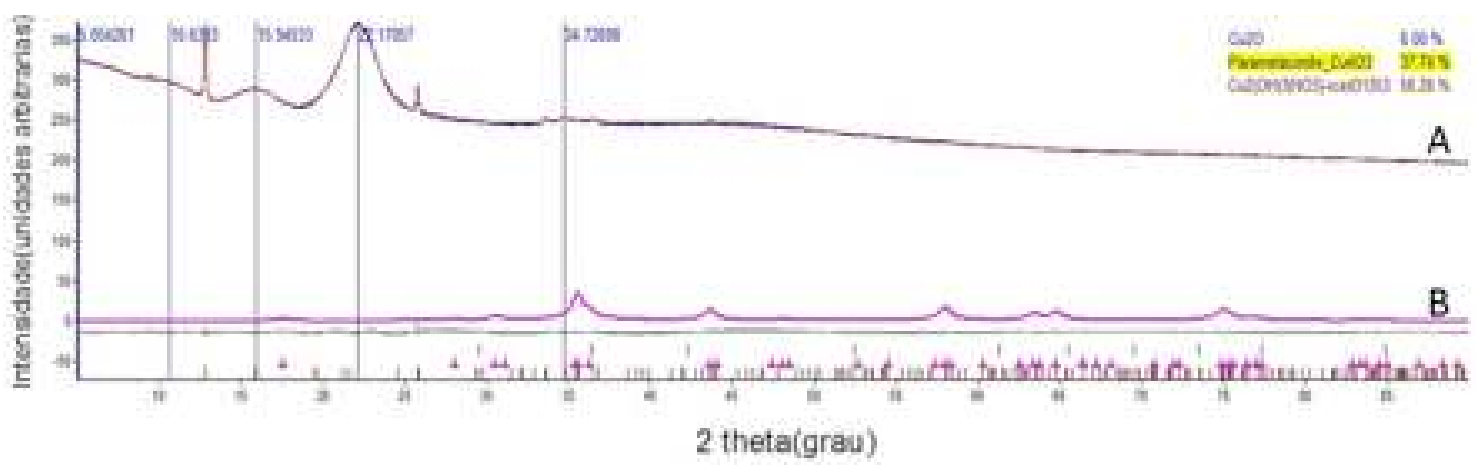

Figura 23. Difratograma da amostra 2 (A) e difratograma da fase paramelaconita (B).

A amostra 3 - (Tabela 1), que passou pelo procedimento de redução com boroidreto de sódio, não apresentou o comportamento esperado, isto é, reduzir o nitrato de cobre até cobre metálico. As três fases sempre presentes até agora estão presentes também nesta amostra, ao passo que duas novas fases apareceram no material. Uma delas é a nitratina $\left(\mathrm{NaNO}_{3}\right)$ e a outra é o nitrato de amônio $\left(\mathrm{NH}_{4} \mathrm{NO}_{3}\right)$. Acredita-se que, 
caso o boroidreto tenha de fato reduzido o triidroxi nitrato de cobre, o mesmo tenha se reoxidado como ocorreu com a amostra 5 (como será visto a seguir). A presença da nitratina teria ocorrido devido ao sódio oriundo do boroidreto de sódio e da solução de hidróxido de amônio, usada em grande quantidade para alcalinizar a solução. As presenças desse agente redutor e do hidróxido de amônio provavelmente também foram responsáveis pela formação do nitrato de amônio. As figuras 24 a 29 ilustram o difratograma da amostra e sua análise no TOPAS.

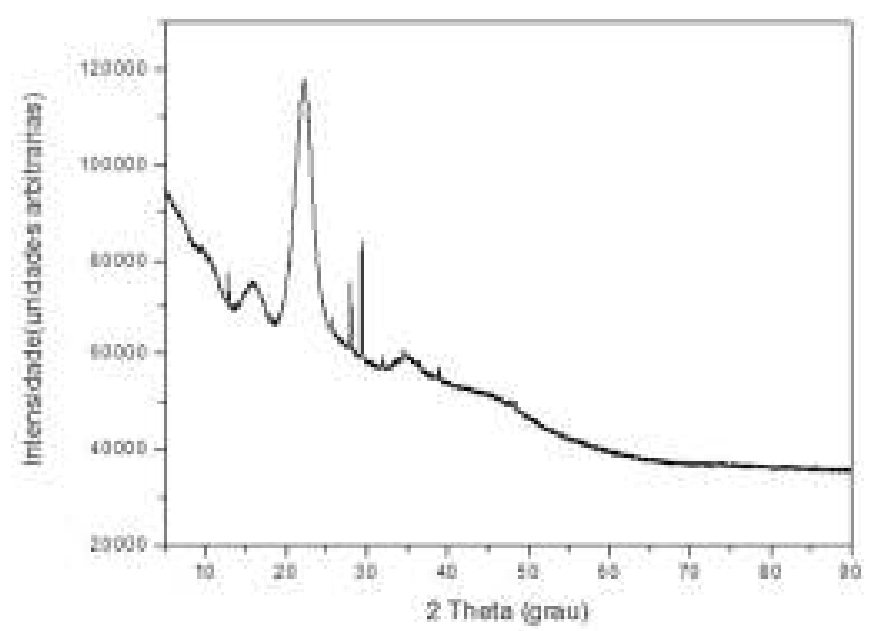

Figura 24. Difratograma da amostra 3.

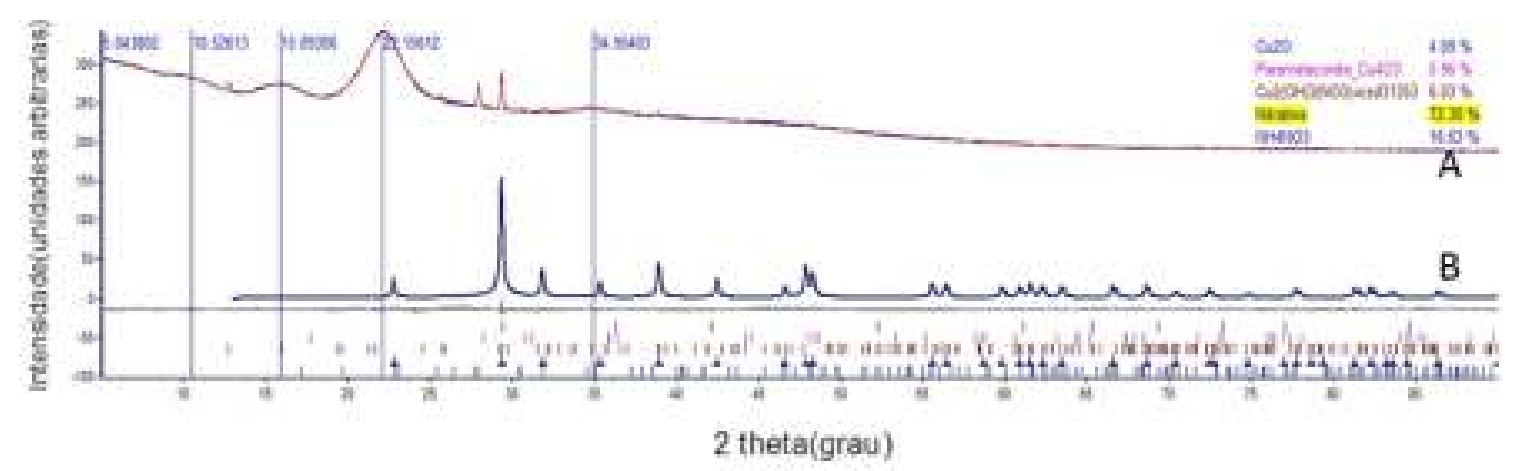

Figura 25. Difratograma da amostra 3 (A) e difratograma da fase nitratina (B). 


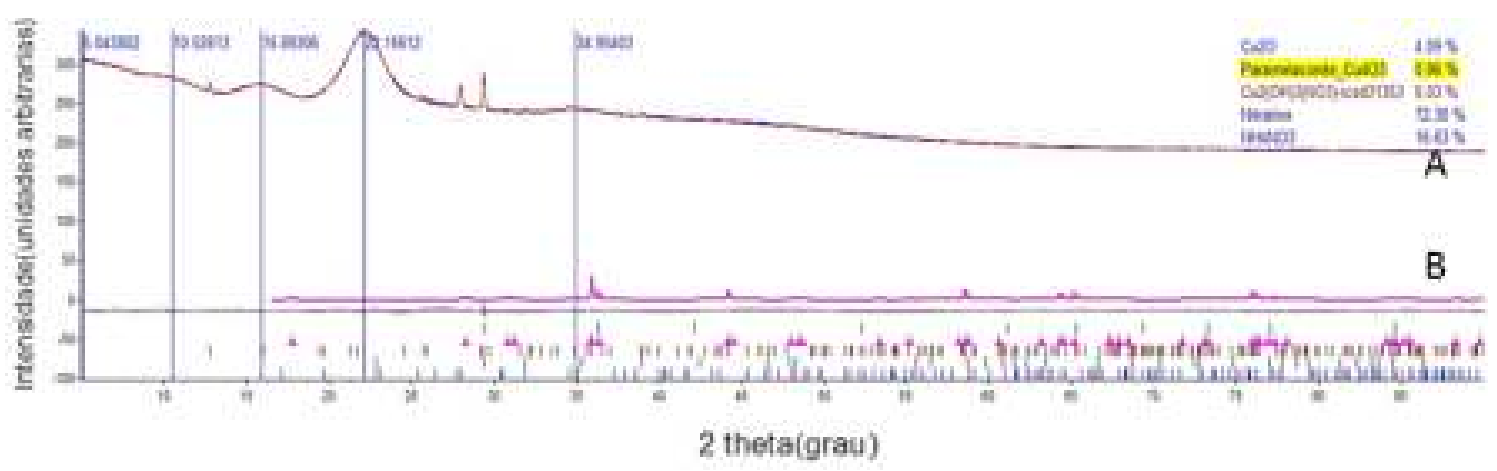

Figura 26. Difratograma da amostra 3 (A), difratograma da fase paramelaconita (B).

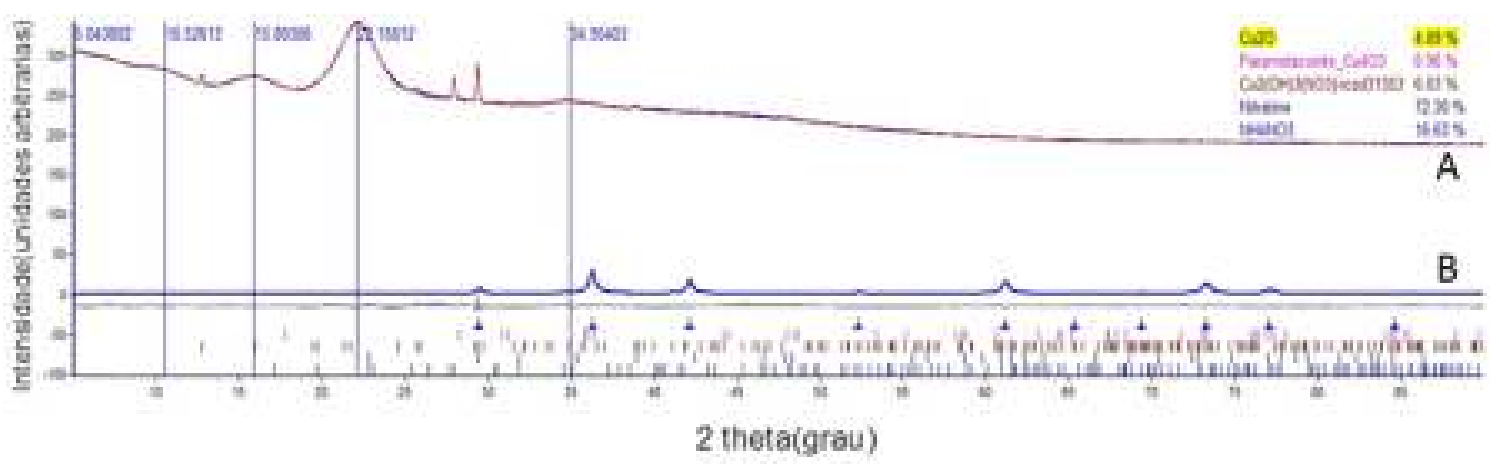

Figura 27. Difratograma da amostra 3 (A) e difratograma da fase $\mathrm{Cu}_{2} \mathrm{O}$ (B).

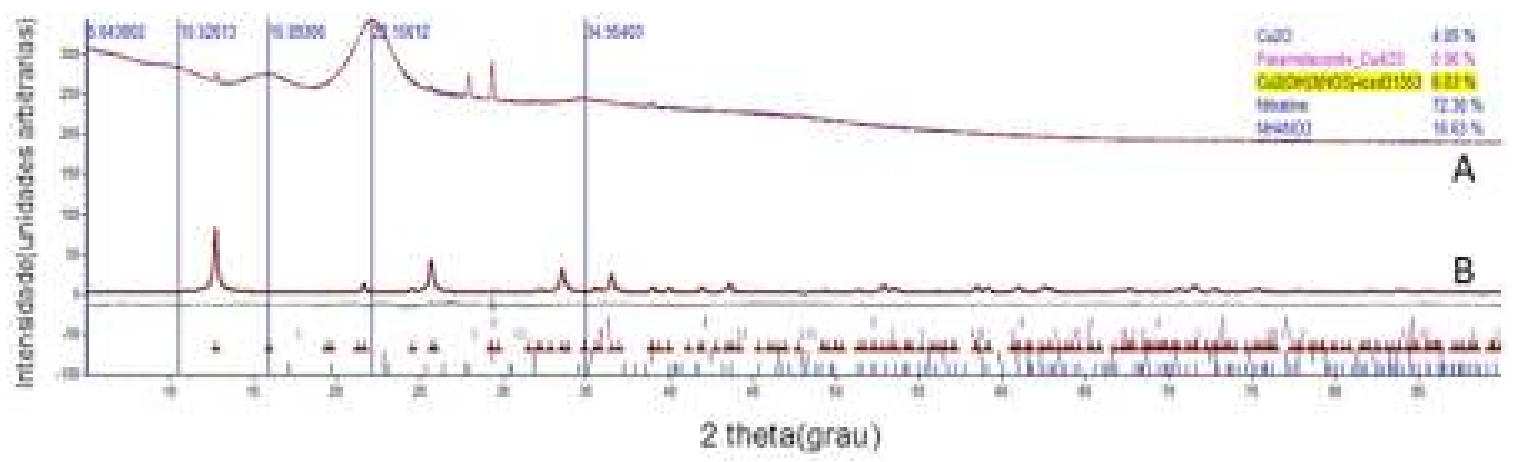

Figura 28. Difratograma da amostra 3 (A) e difratograma da fase triidroxi nitrato de cobre II (B). 


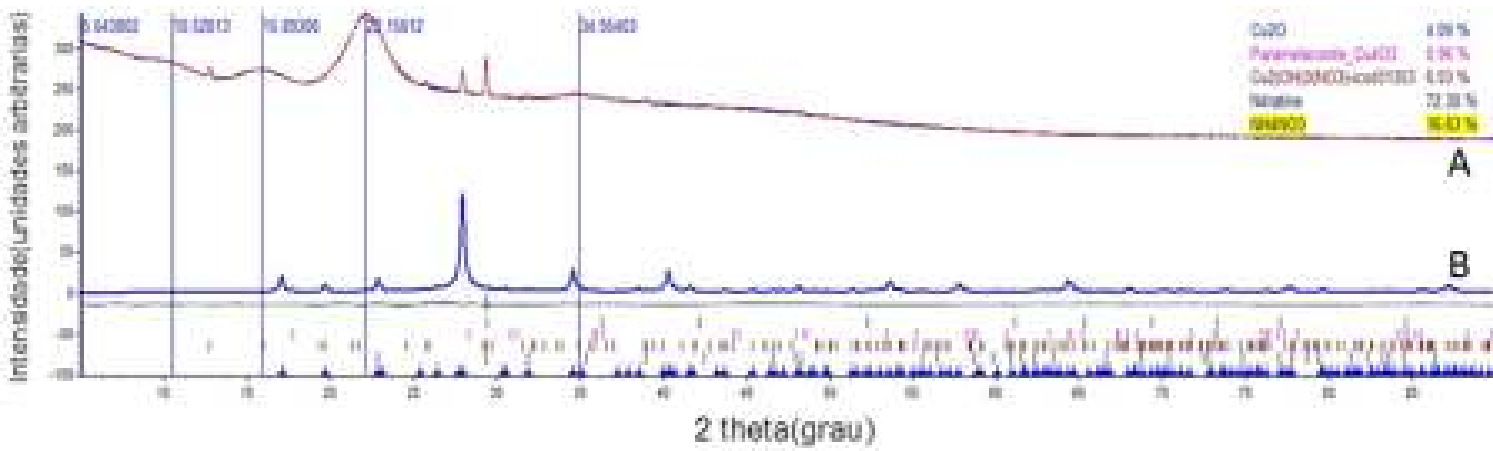

Figura 29. Difratograma da amostra 3 (A) e difratograma da fase nitrato de amônio (B).

Dessa forma, concluiu-se que esse método não foi bem sucedido, uma vez que não foi capaz de reduzir o triidroxi nitrato de cobre e também gerou resíduos. Este método de redução com auxílio de boroidreto de sódio foi, portanto, descartado.

Um quarto pedaço bambu foi preparado para que pudéssemos realizar uma tentativa de redução do $\mathrm{Cu}_{2}\left(\mathrm{NO}_{3}\right)(\mathrm{OH})_{3}$ (amostra 4 - Tabela 1). Esse quarto pedaço foi preparado em condições similares aos dois primeiros (amostras 1 e 2), porém com $0,5 \mathrm{M}$ de concentração de nitrato de cobre. A figura 30 ilustra o difratograma da amostra 4 pós-impregnação e demonstra que novamente obteve-se um resultado similar aos anteriores.

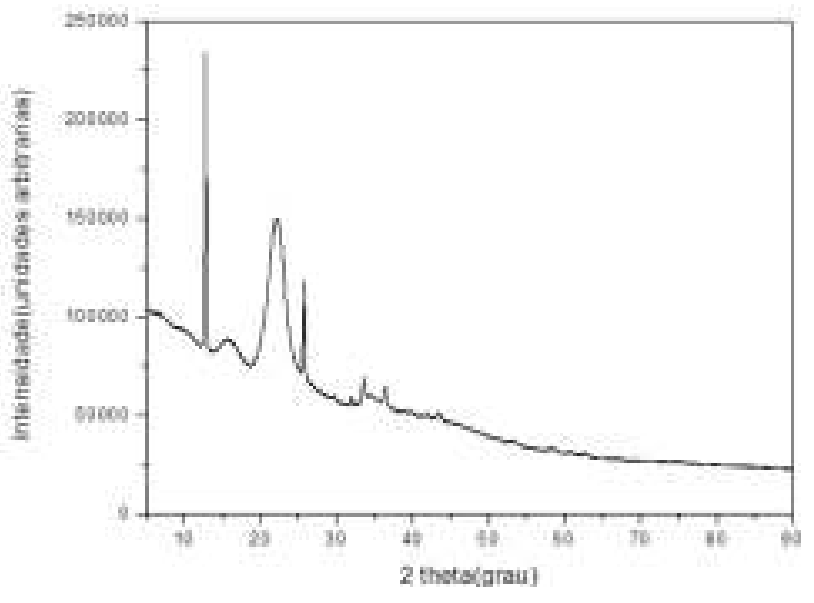

Figura 30. Difratograma da amostra 4 antes da reoxidação.

Ao realizarmos o procedimento de redução descrito na seção 2.4, o bambu apresentou uma cor escura, porém no dia seguinte, antes de realizarmos a difração de raios-X, o bambu apresentou novamente uma cor esverdeada. Desse modo, acreditava- 
se que pudesse ter havido uma reoxidação, o que parece ter se confirmado com o resultado obtido na difração, semelhante ao anterior e sem cobre metálico, como podese verificar na figura 31 .

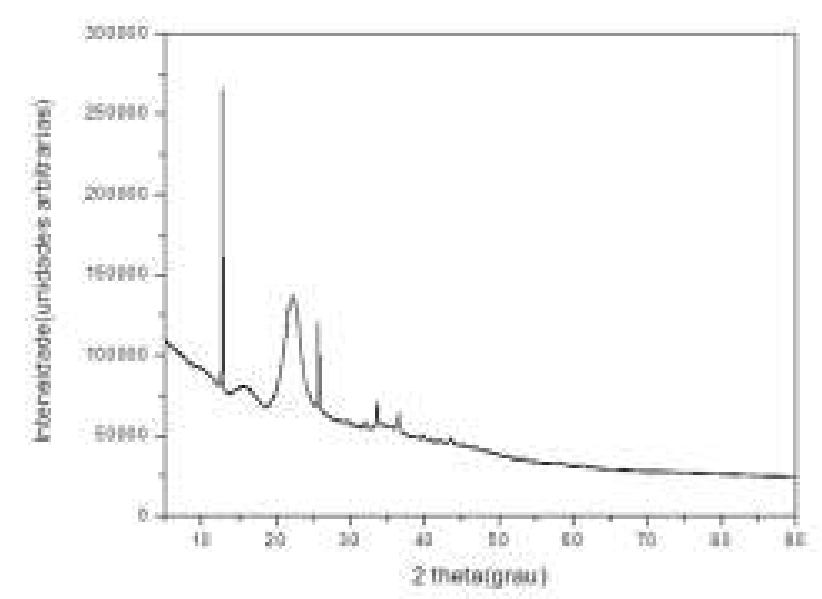

Figura 31. Difratograma da amostra 4 após a reoxidação.

Devido à difração ser uma técnica de penetração limitada (aproximadamente $200 \mu \mathrm{m}$ ), não seria possível determinar se a impregnação fora superficial ou se houvera uma penetração. Assim sendo, a amostra de bambu 1 foi cortada ao meio e submetida a uma nova difração, sendo chamada doravante de amostra 5. Observa-se nas figuras $32 \mathrm{e}$ 33 que o padrão de difração continua semelhante, porém os picos anteriores decresceram em tamanho. Isso era esperado, pois é intuitivo compreender que haveria uma quantidade maior do material impregnado na superfície, e que apenas uma quantidade menor seria capaz de adentrar os canais. 


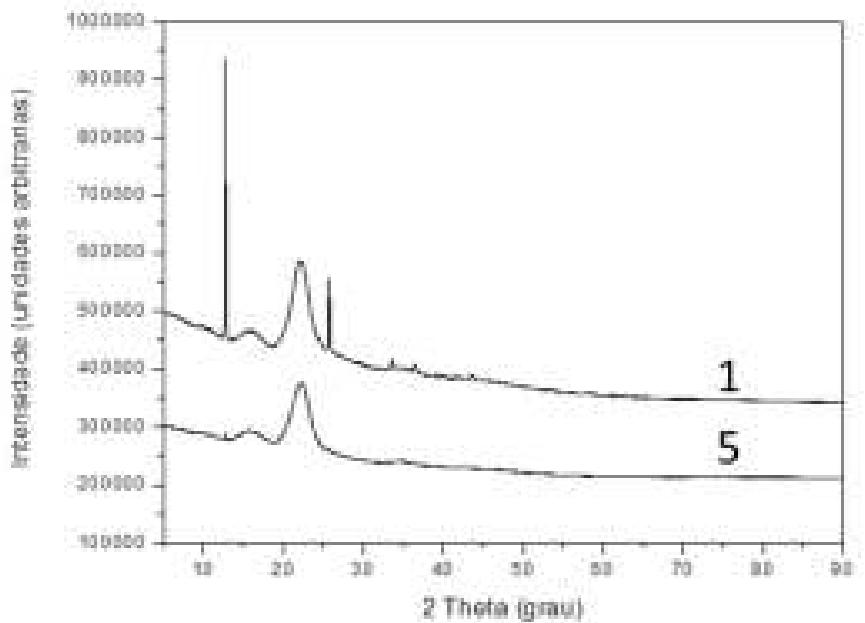

Figura 32. Difratogramas das amostras 1 e 5.

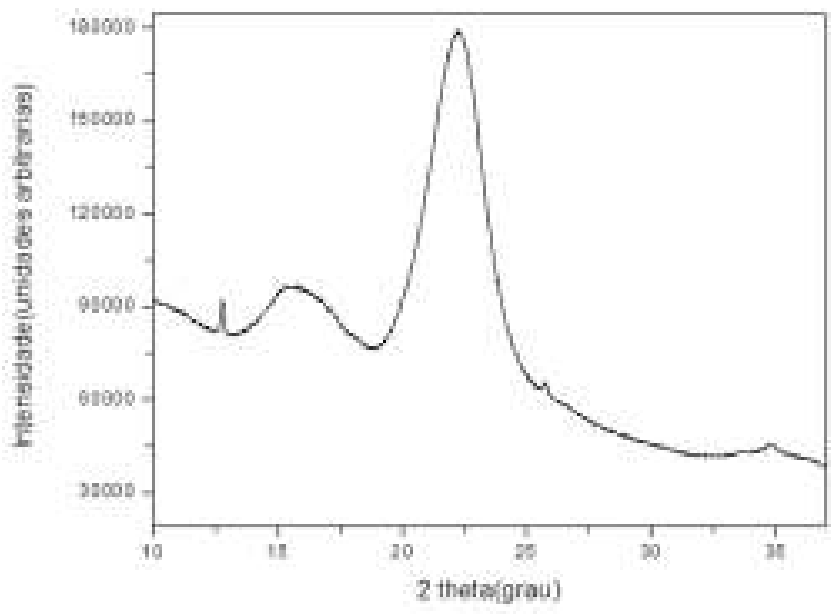

Figura 33. Difratograma da amostra 5 em maior ampliação.

Devido a menor quantidade no interior do bambu, foi possível identificar apenas a fase que apresentava o maior pico, o Triidroxi nitrato de cobre II, o que pode ser observado na figura 34 . 


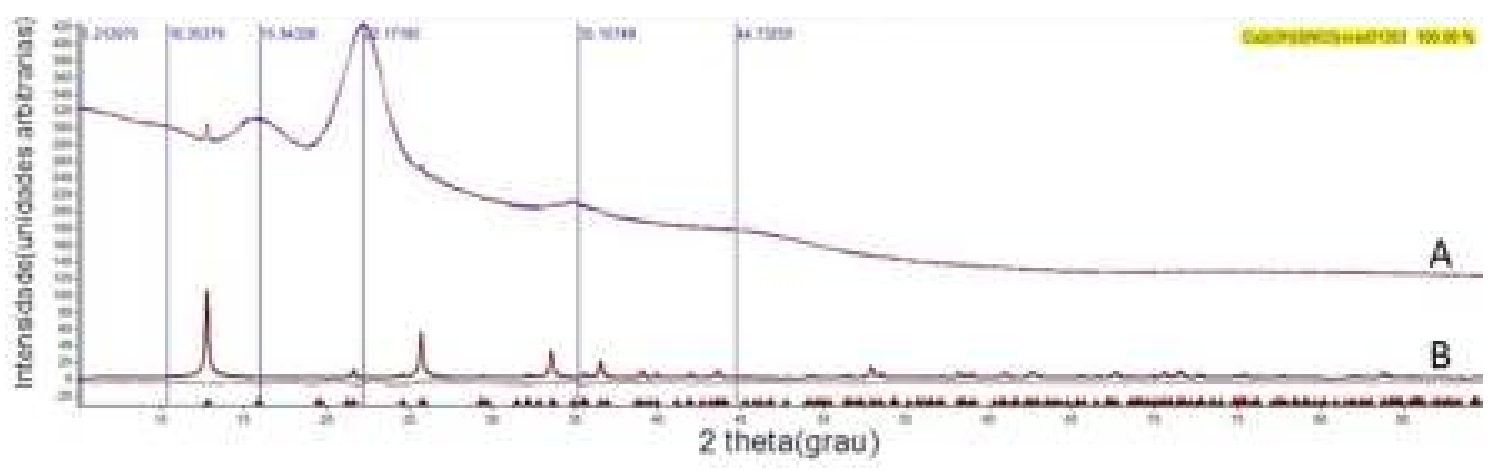

Figura 34. Difratograma da amostra 5 (A) e difratograma da fase triidroxi nitrato de cobre II (B).

A tabela 2 sumariza os resultados obtidos por difração de raios-X.

Tabela 2. Nome da amostra, fases cristalinas, tamanho de cristalito e parâmetros de ajuste obtidos pelo TOPAS.

\begin{tabular}{|c|c|c|c|c|}
\hline $\begin{array}{l}\text { NOME DA } \\
\text { AMOSTRA }\end{array}$ & $\begin{array}{c}\text { FASES } \\
\text { IDENTIFICADAS }\end{array}$ & $\begin{array}{c}\text { TAMANHO MÉDIO } \\
\text { DO CRISTALITO } \\
(\mathrm{nm})\end{array}$ & GOF & Rwp \\
\hline \multirow{3}{*}{1} & $\mathrm{Cu}_{2} \mathrm{O}$ & 41,0 & \multirow{3}{*}{2,89} & \multirow{3}{*}{1,17} \\
\hline & $\mathrm{Cu}_{4} \mathrm{O}_{3}$ & 12,4 & & \\
\hline & $\mathrm{Cu}_{2}(\mathrm{OH})_{3} \mathrm{NO}_{3}$ & 164,9 & & \\
\hline \multirow{3}{*}{2} & $\mathrm{Cu}_{2} \mathrm{O}$ & 34,7 & \multirow{3}{*}{3,46} & \multirow{3}{*}{1,50} \\
\hline & $\mathrm{Cu}_{4} \mathrm{O}_{3}$ & 9,9 & & \\
\hline & $\mathrm{Cu}_{2}(\mathrm{OH})_{3} \mathrm{NO}_{3}$ & 238 & & \\
\hline \multirow{5}{*}{3} & $\mathrm{Cu}_{2} \mathrm{O}$ & 26,2 & \multirow{5}{*}{2,01} & \multirow{5}{*}{0,86} \\
\hline & $\mathrm{Cu}_{4} \mathrm{O}_{3}$ & 9,5 & & \\
\hline & $\mathrm{Cu}_{2}(\mathrm{OH})_{3} \mathrm{NO}_{3}$ & 63,2 & & \\
\hline & Nitratina & 107,4 & & \\
\hline & $\mathrm{NH}_{4} \mathrm{NO}_{3}$ & 55,9 & & \\
\hline \multirow{3}{*}{4} & $\mathrm{Cu}_{2} \mathrm{O}$ & 40,2 & \multirow{3}{*}{3,40} & \multirow{3}{*}{1,48} \\
\hline & $\mathrm{Cu}_{4} \mathrm{O}_{3}$ & 9,6 & & \\
\hline & $\mathrm{Cu}_{2}(\mathrm{OH})_{3} \mathrm{NO}_{3}$ & 54,3 & & \\
\hline 5 & $\mathrm{Cu}_{2}(\mathrm{OH})_{3} \mathrm{NO}_{3}$ & 95,4 & 2,58 & 1,24 \\
\hline
\end{tabular}

Vale ressaltar que o parâmetro "GOF" significa goodness of fitting, é considerado excelente entre 1 e 1,5; porém para amostras com tempo de análise alto é aceitável que sejam mais altos. Já o parâmetro Rwp - weighted profile $R$ factor - 
representa o erro residual quadrático ponderado. Uma análise é considerada excepcional caso seu Rwp $<15$.

O tempo de cada análise das amostras foi de aproximadamente $28 \mathrm{~h}$, o que justifica os valores relativamente altos de GOF. Todavia, todas as análises apresentaram Rwp $<2$, o que indica uma excelente qualidade do ajuste.

A tabela 3 associa as fases identificadas com os picos característicos identificados.

Tabela 3. Fases identificadas e picos característicos identificados

\begin{tabular}{|l|c|c|c|}
\hline \multirow{2}{*}{ FASES IDENTIFICADAS } & \multicolumn{3}{c|}{ 2 $\boldsymbol{\theta}$ - picos característicos identificados $\left(^{\circ}\right)$} \\
\hline $\mathrm{Cu} 2 \mathrm{O}$ & 36,3 & 42,1 \\
\hline $\mathrm{Cu}_{4} \mathrm{O}_{3}$ & \multicolumn{3}{|c|}{44,5} \\
\hline $\mathrm{Cu}_{2}(\mathrm{OH})_{3} \mathrm{NO}_{3}$ & 12,8 & 25,8 & 33,5 \\
\hline $\mathrm{Nitratina}$ & 29,6 & 32,0 & 39,3 \\
\hline $\mathrm{NH} 4 \mathrm{NO}_{3}$ & \multicolumn{2}{|c|}{27,8} & 35,0 \\
\hline
\end{tabular}

Vale ressaltar que alguns dos picos característicos foram identificados apenas pelo TOPAS, dessa forma nem todos são claramente visíveis nos seus respectivos gráficos.

\section{2 - Microtomografia de Raios-X}

Ao interagir com a matéria, os raios-X são absorvidos/atenuados de diferentes maneiras. A depender do ângulo em que interage com a amostra, a intensidade da radiação que chega ao detector pode ser comparada com a intensidade original. Desse modo há uma coleta de diferentes imagens do mesmo, para que, a partir disso, elas possam ser convertidas em seções que representam uma imagem tridimensional.

O objetivo da microtomografia é realizar um mapeamento da estrutura da amostra de bambu, de forma a avaliar a distribuição das fases de cobre impregnadas. Como o mapeamento é feito por uma avaliação do atenuamento dos raios-X atravessantes, o cobre, por ser um elemento muito mais pesado do que os materiais 


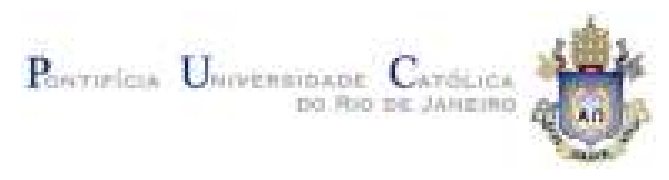

geralmente encontrados no bambu, seria capaz de atenuar muito mais a radiação do que o bambu, dessa forma as estruturas mais densas - regiões mais claras - estariam relacionadas ao cobre.

Diferentemente da técnica de difração de raios-X, todavia, não é possível identificar as diferentes fases do cobre, todas apareceriam da mesma forma. Vale ressaltar que o limite de resolução dessa análise foi de $20 \mu \mathrm{m}$ e que as fases identificadas por DRX apresentaram tamanhos de cristalitos nanométricos, pode-se supor que o método não foi capaz de identificar todo o material impregnado, mas apenas agregados.

A figura 35 ilustra a tomografia de uma amostra de bambu puro feito pelo grupo anterior $^{[13]}$, na escala da imagem, quanto mais clara, mais densa é aquela área, dessa forma. Pode-se, então, observar que há uma diferença de densidade natural ao bambu, além de ser possível diferenciar a matriz do bambu (mais escura) das fibras (mais clara), além de ser possível identificar os canais xilema e floema que atravessam o bambu.

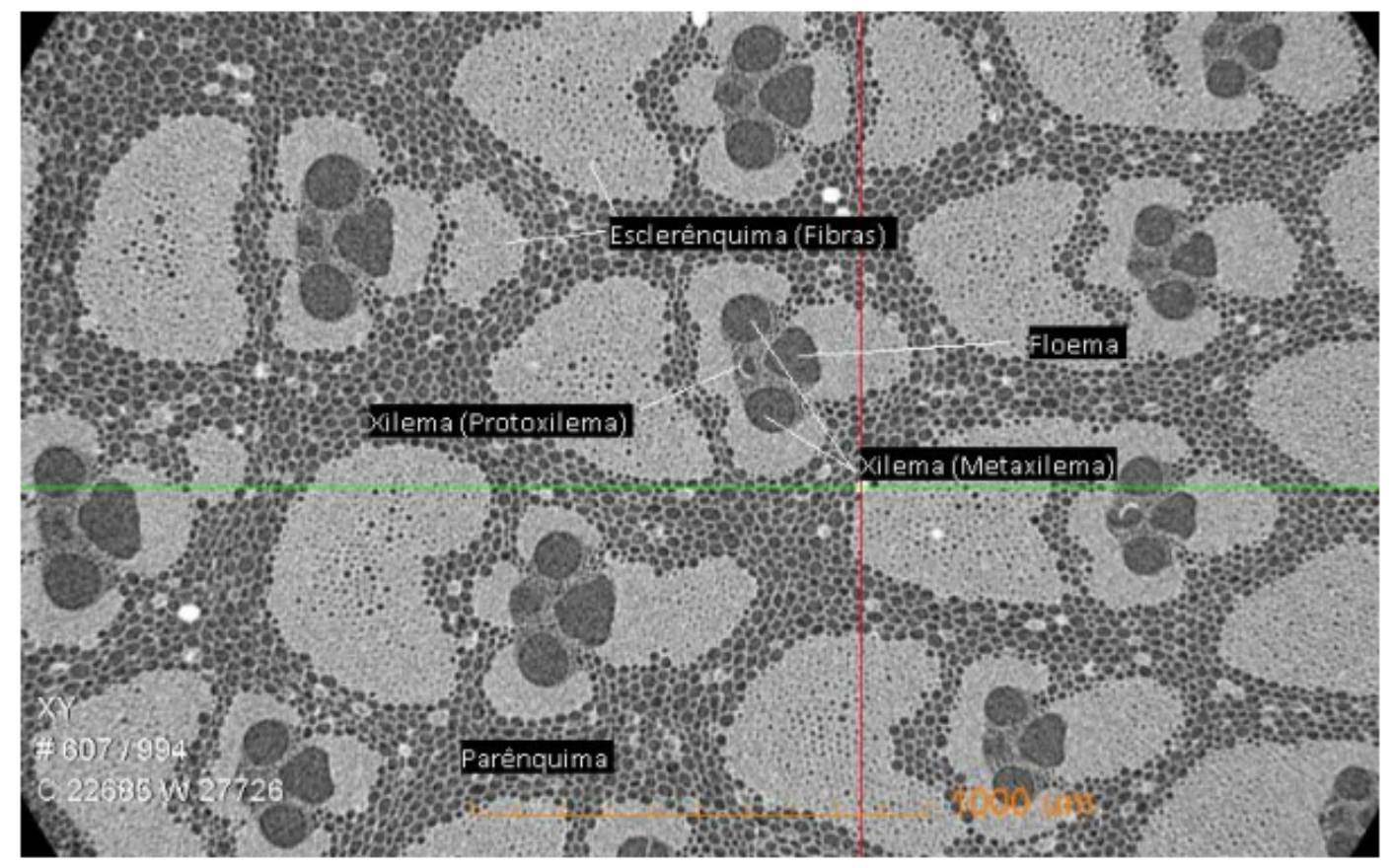

Figura 35. Imagem de tomografia do bambu identificando os canais onde houve, posteriormente, preenchimento pelo cobre. ${ }^{[13]}$ 
O pedaço escolhido para a microtomografia foi a amostra 4. A figura 35 retrata a estrutura interna do bambu conforme foi construída pelo tomógrafo, e cortada com durante o processamento de imagem no software Versa. As fases de cobre estão representadas pelas áreas em branco evidenciadas na figura 36 .

Acreditava-se a priori que a penetração do cobre ocorreria preferencialmente pelos canais do bambu, os quais devido ao corte estavam expostos nas duas laterais. Essa suposição foi corroborada pelos resultados que mostram claramente um excesso de cobre até aproximadamente $1 \mathrm{~mm}$ de profundidade nas laterais, conforme evidenciado pela seta 3 na figura 36, porém também ao longo de alguns canais do bambu por todo o comprimento. Ambas as situações podem ser observadas na figura 37 ressaltadas pelas setas.

É possível ver que próximo à superfície do canal há uma região muito mais clara e densa correspondente ao cobre, a seta 2 indica um desses canais que conseguiram ser penetrados, ficando evidente pela linha mais clara que se estende através do material. A seta 1 mais uma vez mostra que o adensamento ocorre próximo aos canais do material e é quase inexistente no resto do mesmo, onde observam-se cores escuras que indicam preenchimento pelo material orgânico do próprio bambu. 


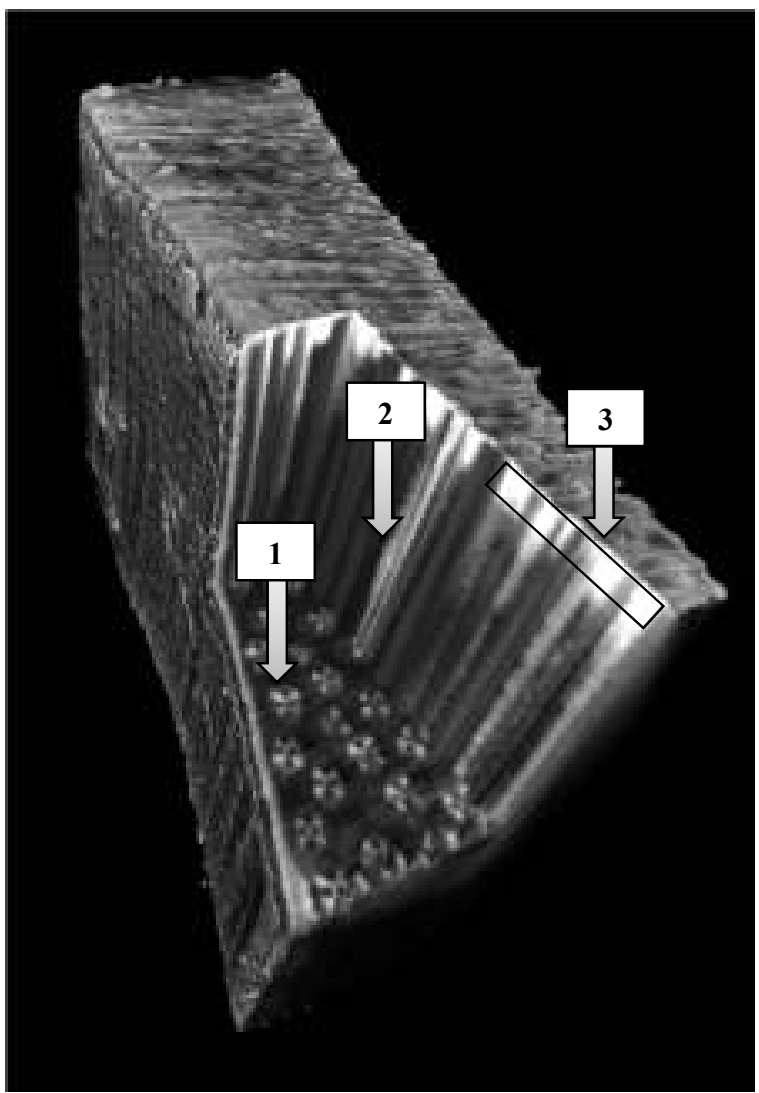

Figura 36. Imagem de microtomografia do bambu (amostra 4) cujas seções estão preenchidas de cobre: 1 - transversal, 2 - longitudinal, 3 - faixa de penetração uniforme na matriz e canais.

As figuras 37 e 38 corroboram as conclusões anteriores, pois é possível observar o acúmulo de cobre nas superfícies do material, o preenchimento de alguns dos canais (como apontado pelas setas) e a concentração do cobre em torno dos canais.

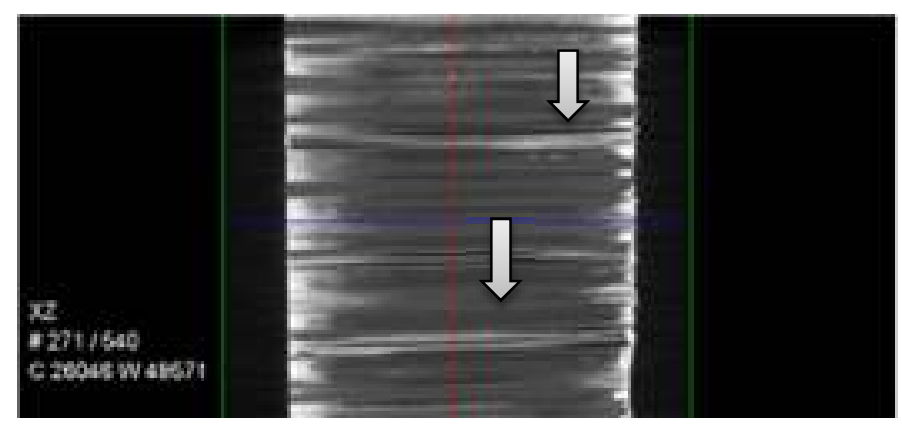

Figura 37. Imagem de microtomografia do bambu (amostra 4), onde é possível observar a penetração próxima à superfície e a penetração por alguns canais indicados por setas. 


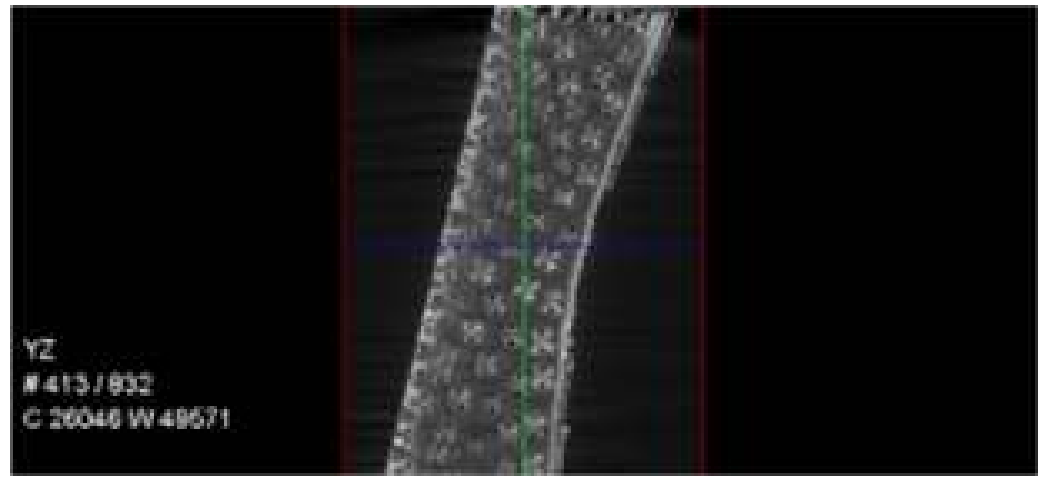

Figura 38. Imagem de microtomografia do bambu (amostra 4) onde é possível observar a seção transversal dos canais e o preenchimento de alguns pelo cobre.

É possível por meio de processamento de imagens remover os volumes menos densos e dessa forma retirar a matriz, deixando apenas o cobre, conforme pode ser observado na figura 39.

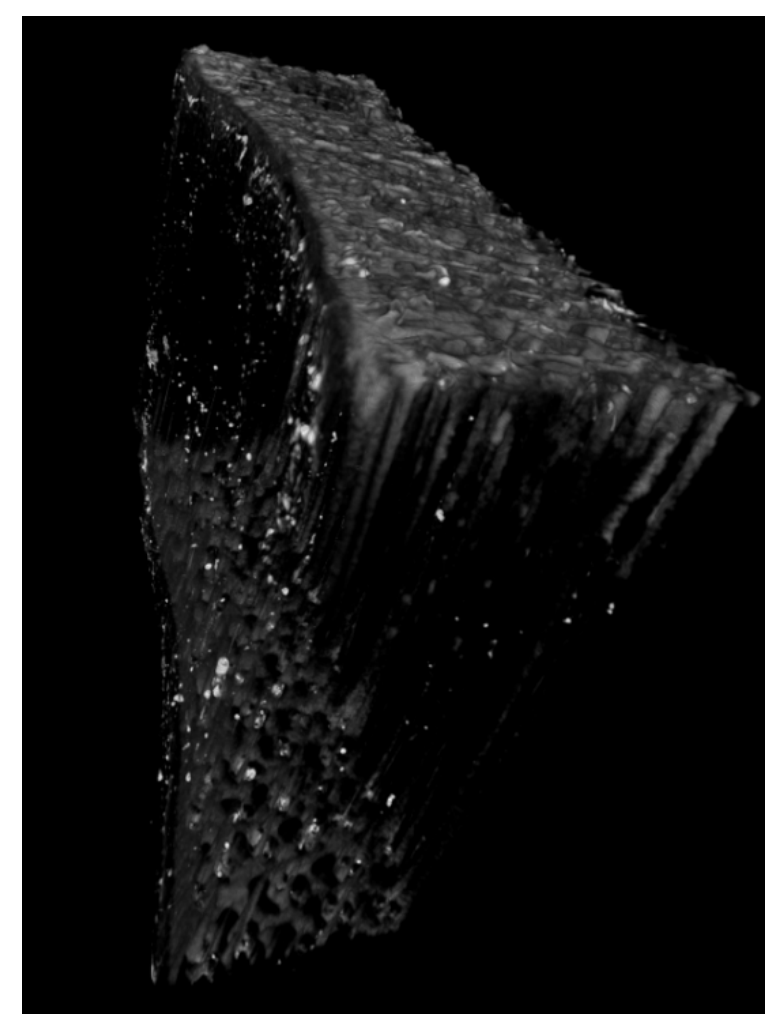

Figura 39. Imagem de microtomografia do bambu (amostra 4) onde a matriz do bambu foi removida, ressaltando a presença do cobre.

Mais uma vez pode-se observar a penetração preferencial pelos canais. Além disso, a Figura 39 deixa evidente um excesso de cobre nas entradas dos canais, o que pode tê-los obstruído, impedindo uma maior penetração das fases de cobre no bambu. 
Observa-se também que não houve homogeneidade na penetração do cobre no interior do bambu. Alguns canais parecem nem ter sido preenchidos, enquanto outros apresentam uma presença maior de cobre, outros até mesmo aparentam terem sido entupidos por um acúmulo de partículas, podendo se ver um claro preenchimento desses canais até o aparecimento de aglomerados de partículas.

Os resultados do tomógrafo parecem ir ao encontro da hipótese inicial sobre os mecanismos de penetração do bambu, embora não seja possível identificar como as três fases presentes de cobre observadas na difração estão distribuídas. Adicionalmente, esses resultados inspiram novas variações no método a serem aplicadas em trabalhos futuros, como por exemplo: uma maneira de limpar previamente os canais de modo a facilitar a penetração do cobre, além de possivelmente uma diminuição da concentração de nitrato usado visando o não acúmulo de cobre nas laterais, que pode estar dificultando a impregnação.

Tal limpeza, porém, não foi realizada propositalmente, visto que se acredita que o amido presente nesses canais funciona como o agente redutor responsável pela conversão do nitrato de cobre nas fases de óxido e cobre metálico ${ }^{[17]}$. Dessa forma uma possível limpeza para a desobstrução dos canais não poderá ser excessiva a ponto de prejudicar a redução ou deverá ser acompanhada de outra modificação que garanta a redução, como por exemplo a adição de outro agente redutor além do etanol na própria solução.

É válido repetir que o limite mínimo de resolução do tomógrafo é $20 \mu \mathrm{m}$, portanto partículas menores do que este valor não apareceriam nas imagens, logo o cobre representado nas imagens pode não ser correspondente ao total que de fato está presente.

Ao compararem-se as imagens com a identificação dos canais do bambu feito pelo grupo anterior ${ }^{[13]}$ (figura 35), pode-se perceber que o preenchimento por cobre ocorreu tanto no xilema quanto no floema. 


\section{Conclusão}

O método desenvolvido foi capaz de realizar uma redução parcial do nitrato de cobre, sendo possível obter nanopartículas de óxido de cobre $\mathrm{I}\left(\mathrm{Cu}_{2} \mathrm{O}\right)$ de diâmetro na faixa de $25 \mathrm{~nm}-41 \mathrm{~nm}$ e nanopartículas de paramelaconita $\left(\mathrm{Cu}_{4} \mathrm{O}_{3}\right)$ de diâmetro $9 \mathrm{~nm}-$ $12 \mathrm{~nm}$, conforme observado pelos resultados obtidos por difração de raios-X. Isso corrobora a teoria de que o amido aliado ao etanol tem uma capacidade redutora, mesmo que não o suficiente para produzir nanopartículas de cobre metálico como objetivado a princípio. Ademais, percebe-se que o método de impregnação não foi capaz de gerar uma penetração homogênea por todo o material, conforme observado pelos resultados de microtomografia.

Para futuros trabalhos, novos métodos de redução do nitrato antes e após a sua impregnação no bambu serão testados, bem como métodos para gerar uma impregnação homogênea no bambu, como um limpeza prévia dos canais, ou uma redução da concentração visando uma possível redução do entupimento dos canais dos bambus. Além disso, faz-se necessário um teste antifungicida nas amostras de bambu preparadas, para que a capacidade antimicrobicida do cobre e seus óxidos seja confirmada. Embora não tenha-se alcançado cobre metálico, o óxido de cobre I foi sintetizado e dessa forma pode já possuir capacidade antimicrobicida ${ }^{[17]}$. Outras possibilidades incluem: uso de diferentes agentes redutores, síntese prévia de nanopartículas e posterior impregnação, usar uma análise de maior resolução na microtomografia.

\section{Referências}

1. ANABIS, JOSÉ MARIANO / RODRIGUES, MARTHO GILBERTO. Amabis e Martho, Fundamentos da Biologia Moderna. Editora Moderna, 2009.

2. MARIANO, N. P. et al. Análise Química do Bambu-Gigante (Dendrocalamus Giganteus Wall. Ex Munro) Em Diferentes Idades. Periódico Ciência 2012 Florestal ISSN: 0103-9954 Ciência Florestal ISSN: 0103-9954.

3. SALAM, KAMESH / PONGEN, ZULU. Handbook on Bamboo. Editado por S. K. Sarma, AFS (Retd.) Consultant, CBTC, 2008. 
4. VAUPE, FRED. Das Bambus-Lexikon. Disponível em: http://www.bambuslexikon.de/dendrocalamus.html. Acesso em 04.09.2016 às 21 horas.

5. PANDE, P. K. Anatomy of Indian Bamboos, Editado por ENVIS Centre on Forestry. 2008.

6. AZZINI, A. et al. Avaliação Quantitativa Da Massa Fibrosa E Vazios Em Colmos

De Bambu, . Publicado em 1990 por Seção de Plantas Fibrosas, Instituto Agronômico (IAC), Caixa Postal 28, ISSN: 13001, Campinas (SP) 1990.

7. VAUPE, FRED. Das Bambus-Lexikon. Disponível em: http://www.bambuslexikon.de/dendrocalamus-giganteus.html. Acesso em 12.09.2016 às 14 horas.

8. SILVA, R. G. et al. Occurrence of Filamentous Fungi on Dendrocalamus Giganteusin Brazil. Publicado no nono congress de bambu mundial, em 2009 (IX World Bamboo Congress, 2009).

9. JUN, SHIN. The World of Bamboo. Disponível em: http://www.chinascenic.com/magazine/the-world-of-bamboo-212.html. Acesso em 17.10.2016 às 17 horas.

10. Ciências Biológicas. Disponível em: http://profaericaciencias.blogspot.com.br/2016/03/a-folha-e-o-orgao-da-planta-onde-se.html. Acesso em 18.11.2016 às 22 horas.

11. LIE W. Anatomy and Properties of Bamboo. Institute of Wood Biology and Wood Preservation of the Federal, Germany Publicado no Inbar: International Network for bamboo and rattan 2008 .

12. LWIN, D. K. M. et al. An Investigation on Morphology, Anatomy and Chemical Properties of Some Myanmar Bamboos, Government of the Union of Myanmar Ministry of Forestry Forest Department Forest Research Institute, feito pelo Departamento Florestal do Ministério dos Recursos Naturais e da Conservação do Meio Ambiente de Myanmar 2001.

13. PANDOLI, O. et al. Colloidal Silver Nanoparticles: an Effective Nano- Filler Material to Prevent Fungal Proliferation in Bamboo. RSC Adv., 2016, 6, 98325 
14. LOPES, JOÃO. Diversidade das Plantas. Disponível em: http://joaolopes 1408aepedome.blogspot.com.br/2012/02/diversidade-das-plantas.html. Acesso em 16.09.2016 às 17 horas.

15. CHEARY, R.W. et al. A Fundamental Parameters Approach to Xray LineProletting. Journal of Applied Crystallography. 25(1992):109\{121, 1992\}.

16. MicDigi. Disponível em:

http://lpdipuc.jimdo.com/portugu\%C3\%AAs/microtomografia/zeiss-xradia-versa-510/. Acesso em 18.11.2016 às 20 horas.

17. KRITHIGA, N. et al. Synthesis, Characterization and Analysis of the Effect of Copper Oxide Nanoparticles in Biological Systems. Publicado em Research Gate 2016. 